\title{
PERFIL CONSTRUTIVO DAS FORTIFICAÇÕES PORTUGUESAS DA CAPITANIA DE PERNAMBUCO APÓS 1654: Após a capitulação holandesa
}

\section{CONSTRUCTIVE PROFILE OF PORTUGUESE FORTIFICATIONS IN CAPPITANIA OF PERNAMBUCO AFTER 1654: After the dutch capitulation}

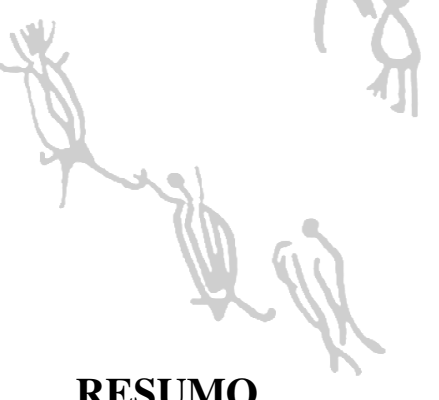

\author{
Manuela Xavier Gomes de Matos $^{1}$ \\ manumatos@uol.com.br \\ Paulo Martin Souto Maior ${ }^{2}$ \\ pmsmaior@yahoo.com
}

\section{RESUMO}

A pesquisa da qual se origina este artigo, o último de uma série de três dos quais dois já se publicaram aqui na Revista Clio Arqueológica, integra um trabalho abrangente que estudou as fortificações construídas na Capitania de Pernambuco entre os séculos XVI e XVII. Este texto abarca especificamente a terceira fase, ou seja, o perfil construtivo de fortificações da antiga Capitania de Pernambuco da segunda metade do século XVII, período após a capitulação holandesa, em 1654. A análise das estruturas das quatro fortificações remanescentes desse período, (Forte de Santa Cruz de Itamaracá - 1654, Forte do Brum 1654, Forte São Tiago da Cinco Pontas - 1684 e Forte Santo Inácio de Loyola de Tamandaré 1654), revelaram que essas construções foram influenciadas por modelos descritos em tratados de fortificação europeus da época. A pesquisa ainda expôs que houve adaptações à realidade de material, mão de obra, recursos e uma postura colonizadora que impôs restrições e adaptações a partir dos modelos europeus. Identificar essas transformações foi o objetivo principal.

Palavras-chave: Fortificações, século XVII, Pernambuco.

\footnotetext{
${ }^{1}$ Discente, Programa de Pós-graduação em Arqueologia, UFPE.

${ }^{2}$ Departamento de Arqueologia, UFPE.
} 


\begin{abstract}
The research from which this article originates, the last in a series of three of which two have already been published here in Clio Arqueológica magazine, integrates a comprehensive work that studied the fortifications built in the Captaincy of Pernambuco between the 16 th and 17 th centuries. This text specifically covers the third phase, that is, the constructive profile of fortifications of the former Captaincy of Pernambuco in the second half of the 17th century, period after the Dutch capitulation, in 1654. The analysis of the structures of the four remaining fortifications of that period, (Forte de Santa Cruz de Itamaracá - 1654, Fort do Brum - 1654, Fort São Tiago da Cinco Pontas - 1684 and Fort Santo Inácio de Loyola de Tamandaré 1654), revealed that these buildings were influenced by models described in European fortification treaties of the time. The research also exposed that there were adaptations to the reality of material, labor, resources and a colonizing posture that imposed restrictions and adaptations based on European models. Identifying these transformations was the main objective.
\end{abstract}

Keywords: Fortifications, 17th century, Pernambuco.

\title{
EFICÁCIA BÉLICA
}

O pressuposto básico de uma fortificação é que esta possa se defender e defender um determinado lugar. Enquanto uma estrutura de defesa consideramos que uma fortificação é o resultado da combinação entre sua configuração geométrica, materiais, ambiente, capital disponível e interesses econômicos e políticos. Consideramos, ainda, que as fortificações integram sistemas defensivos. Registrase, no entanto, que é recorrente, nos estudos sobre o tema, que um sistema defensivo é um conjunto de estruturas de defesa. Nessa pesquisa, contudo, refinou-se o conceito de sistema defensivo que passou a ser considerado como "uma ação combinada e concomitante entre fortificações, tropas e, principalmente, embarcações (devendo-se levar em conta ainda a quantidade e qualidade dos 
armamentos que dispunham cada um dos elementos desta tríade)"”3. E ainda, [nessa pesquisa] a capacidade de se defender passou a ser avaliada pela eficácia bélica da fortificação, ou seja, pela sua capacidade de se defender, e essa capacidade está relacionada a três fatores: Tipologia de Fortificação, Modelo de Configuração Geométrica e Grau de Obediência ao Modelo Europeu.

Dentre as dez fortificações do terceiro sistema defensivo português em Pernambuco, apenas quatro apresentam remanescentes que puderam ser estudados: o Forte de Santa Cruz de Itamaracá, o Forte do Brum e o Forte de Santo Inácio de Loyola de Tamandaré, construídos em 1654; e o Forte de São Tiago das Cinco Pontas, construído a partir de 1684 (Figura 1).

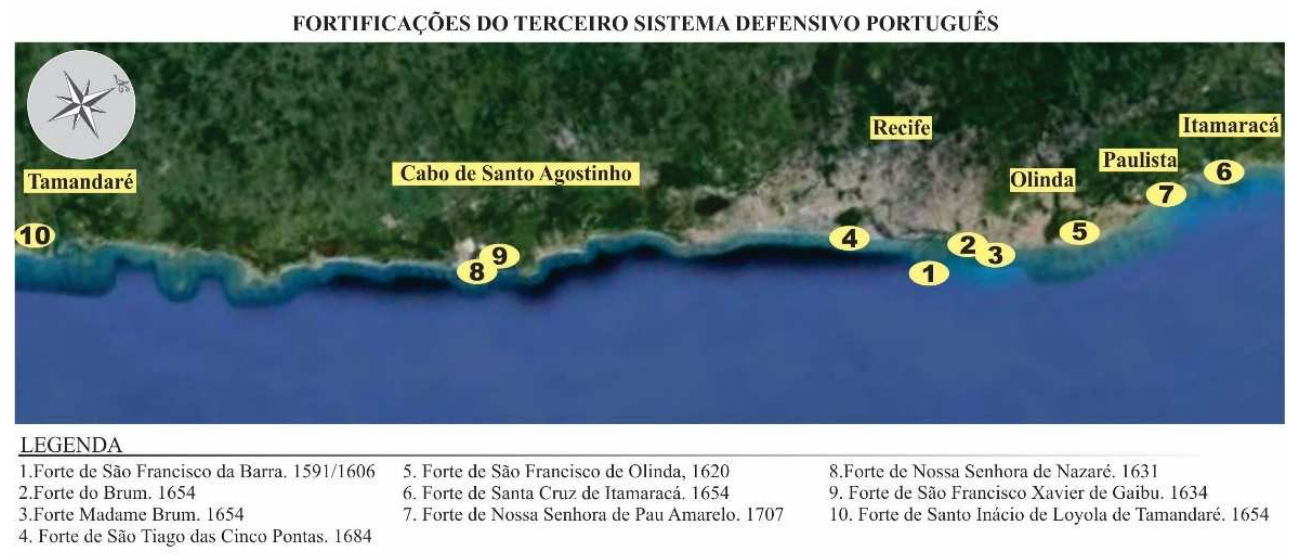

Figura 1. Localização das fortificações construídas/reconstruídas pelo colonizador português após a capitulação holandesa. O Forte de Santa Cruz de Itamaracá; o Forte do Brum; e, o Forte de Santo Inácio de Loyola de Tamandaré, de 1654; e o Forte de São Tiago das Cinco Pontas, de 1684.

\footnotetext{
${ }^{3}$ Tonera, 2005: p. 2.
} 


\section{Fortificações Portuguesas em Pernambuco após 1654}

\section{Forte de Santa Cruz de Itamaracá. 1654}

O Forte de Santa Cruz de Itamaracá foi construído pelos colonizadores portugueses, a partir de 1654, sobre o Forte Orange, de origem holandesa. Está localizado na extremidade sul da Ilha de Itamaracá, litoral norte do Estado de Pernambuco, distante cerca de $40 \mathrm{~km}$ do Recife.

\section{Cronologia}

Em 1654, com a capitulação holandesa, o Forte Orange, construído pelos holandeses, foi abandonado e foi ocupado e reconstruído pelo colonizador português. A partir de 1682, passou a ser chamado Forte de Santa Cruz de Itamaracá. Ao longo dos séculos XVII, XVIII e XX, há vários registros de ter sido objeto de reformas (Figura 2). Em 1938, foi tombado pelo IPHAN.

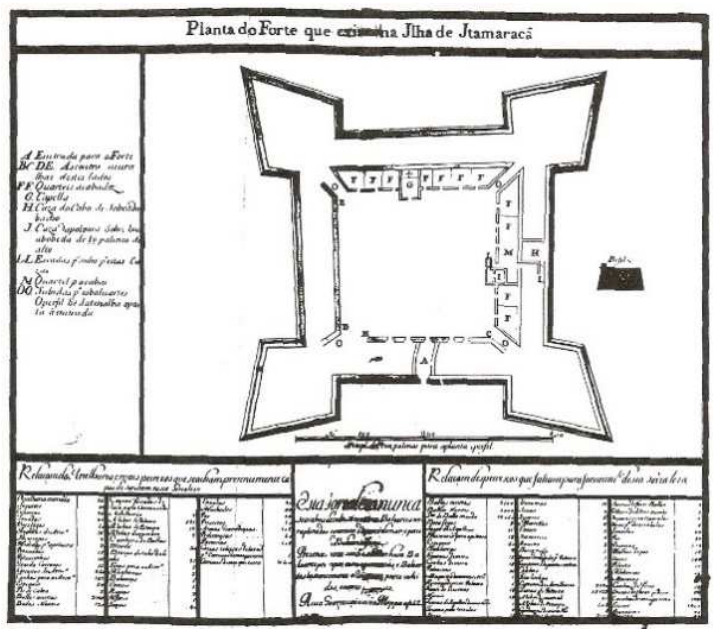

Figura 2. Forte de Santa Cruz de Itamaracá. Planta de 1763 (Acervo do IPHAN. Caixa 8 de $\mathrm{A}$ a $\mathrm{H}$ ). 
Registra-se que em 1968 foram realizadas prospecções arqueológicas na capela e praça de armas; em 1972/73, também houve trabalhos de arqueologia realizados pelo arqueólogo Marcos Albuquerque; e a partir do ano 2000 teve início o "Projeto Forte Orange", um projeto de pesquisa arqueológica realizado pela Universidade Federal de Pernambuco (UFPE) em cooperação com Amsterdams Archeologisch Centrum, da Universidade de Amsterdã.

\section{Configuração Geométrica}

O Forte de Santa Cruz de Itamaracá é uma fortificação do tipo Fortificação Moderna, abaluartada, incluída na tipologia de Castelo ou Cidadela, segundo Scamozzi, e na tipologia de Forte quadrantal, segundo Goldman. Apresenta planta com formato de polígono quadrangular. Suas dimensões e proporções estão apresentadas nas Tabelas 1 e 2 e Figura 3.

Os principais itens que compõe a fortificação são: reparo contendo baluarte, com suas faces e flancos, e cortina. Sobre o terrapleno, há parapeito em alvenaria em perímetro da fortificação, com canhoneiras. A fortificação ainda conta com vestígios de obras externas: são elas: fosso e base em pedra para paliçada. Sua muralha é inclinada, apresentando caimento médio de $78,72^{\circ}$. Ao longo de todo reparo, há um cordão em pedra que sinaliza o fim do reparo e início do parapeito. Grosso modo, a fortificação mede 126 metros de comprimento, 128 metros de largura e 6,30 metros de altura, do solo atual até o cordão em pedra. 


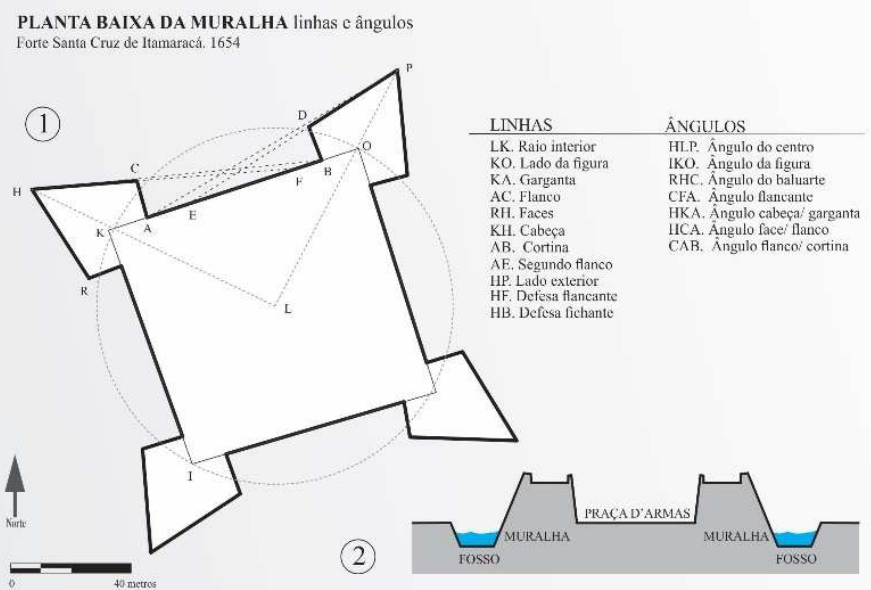

Figura 3. (1) Planta baixa da muralha Forte de Santa Cruz de Itamaracá, com indicação das linhas e ângulos, obtidos com levantamento topográfico (usando Estação Total), e (2) corte esquemático da relação entre a muralha, o fosso e praça d'armas.

\begin{tabular}{|l|c|c|c|c|c|c|c|c|c|}
\hline & \multicolumn{9}{|c|}{ Lados (metro) } \\
\cline { 2 - 10 } & $\mathbf{1}$ & $\mathbf{2}$ & $\mathbf{3}$ & $\mathbf{4}$ & $\mathbf{5}$ & $\mathbf{6}$ & $\mathbf{7}$ & $\mathbf{8}$ & Média \\
\hline Raio interior & 58,87 & 60,35 & 58,87 & 60,35 & & & & & 59,61 \\
\hline Lado da figura & 83,83 & 82,01 & 86,85 & 84,48 & & & & & 84,29 \\
\hline Garganta & 12,78 & 12,74 & 13,33 & 12,5 & 9,65 & 11,58 & 10,92 & 10,26 & 11,72 \\
\hline Flanco & 11,87 & 12,76 & 12,53 & 11,43 & 13,91 & 13,75 & 12,35 & 11,84 & 12,56 \\
\hline Face & 34,44 & 35,37 & 35,19 & 34,38 & 34,71 & 34,87 & 34,67 & 34,86 & 34,81 \\
\hline Cabeça & 28,87 & 28,59 & 32,32 & 31,05 & & & & & 30,21 \\
\hline Cortina & 59,85 & 61,32 & 61,46 & 60,72 & & & & & 60,84 \\
\hline Segundo flanco & 8,64 & 9,43 & 24,32 & 15,04 & 1,53 & 11,57 & 14,4 & 8,21 & 11,64 \\
\hline Lado exterior & 126,2 & 126,33 & 128,47 & 126,88 & & & & & 126,97 \\
\hline Defesa flancante & 96,08 & 96 & 95,5 & 95,21 & 97,36 & 96,08 & 97,18 & 97,06 & 96,31 \\
\hline Defesa fichante & 86,84 & 86,28 & 88,08 & 81,99 & 95,56 & 85,9 & 82,87 & 72,68 & 85,03 \\
\hline
\end{tabular}

Tabela 1. Medidas lineares aferidas em campo por levantamento topográfico, com utilização de Estação Total. Forte de Santa Cruz de Itamaracá.

\begin{tabular}{|l|c|c|c|c|c|c|c|c|c|}
\hline & $\begin{array}{c}\text { Ângulo } \\
\mathbf{1}\end{array}$ & $\begin{array}{c}\text { Ânulo } \\
\mathbf{2}\end{array}$ & $\begin{array}{c}\text { Ânulo } \\
\mathbf{3}\end{array}$ & $\begin{array}{c}\text { Ângulo } \\
\mathbf{4}\end{array}$ & $\begin{array}{c}\text { Ânulo } \\
\mathbf{5}\end{array}$ & $\begin{array}{c}\text { Angulo } \\
\mathbf{6}\end{array}$ & $\begin{array}{c}\text { Ângulo } \\
\mathbf{7}\end{array}$ & $\begin{array}{c}\text { Ângulo } \\
\mathbf{8}\end{array}$ & Média \\
\hline Ângulo do centro & $91,8^{\circ}$ & $91,6^{\circ}$ & $87,6^{\circ}$ & $88,9^{\circ}$ & & & & & $90,0^{\circ}$ \\
\hline Ângulo da figura & $88,8^{\circ}$ & $89,5^{\circ}$ & $88,4^{\circ}$ & $93,3^{\circ}$ & & & & & $90,0^{\circ}$ \\
\hline Ângulo baluarte & $61,9^{\circ}$ & $61,1^{\circ}$ & $56,6^{\circ}$ & $62,8^{\circ}$ & & & & & $60,6^{\circ}$ \\
\hline Ângulo flancante & $15,2^{\circ}$ & $12,8^{\circ}$ & $17^{\circ}$ & $18,3^{\circ}$ & $12,1^{\circ}$ & $13,9^{\circ}$ & $13,5^{\circ}$ & $14,5^{\circ}$ & $14,7^{\circ}$ \\
\hline
\end{tabular}




\begin{tabular}{|l|c|c|c|c|c|c|c|c|c|}
\hline $\begin{array}{l}\text { Ângulo } \\
\text { cabeça/garganta }\end{array}$ & $133,6^{\circ}$ & $133,1^{\circ}$ & $134,5^{\circ}$ & $136,7^{\circ}$ & $135,6^{\circ}$ & $134,9^{\circ}$ & $136,2^{\circ}$ & $135,4^{\circ}$ & $135,0^{\circ}$ \\
\hline $\begin{array}{l}\text { Angulo } \\
\text { face/flanco }\end{array}$ & $102,5^{\circ}$ & $103,5^{\circ}$ & $101,5^{\circ}$ & $104,4^{\circ}$ & $101,8^{\circ}$ & $99,4^{\circ}$ & $100,8^{\circ}$ & $101,4^{\circ}$ & $101,9^{\circ}$ \\
\hline $\begin{array}{l}\text { Angulo } \\
\text { flanco/cortina }\end{array}$ & $87,3^{\circ}$ & $88,5^{\circ}$ & $87,2^{\circ}$ & $87,3^{\circ}$ & $90,5^{\circ}$ & $83,2^{\circ}$ & $87,3^{\circ}$ & $86,5^{\circ}$ & $87,2^{\circ}$ \\
\hline
\end{tabular}

Tabela 2. Medidas angulares aferidas em campo por levantamento topográfico, com utilização de Estação Total. Forte de Santa Cruz de Itamaracá.

\section{Escolha dos materiais construtivos}

O Forte de Santa Cruz de Itamaracá está construído em terra e encamisado em alvenaria de pedra com argamassa de barro e cal. A partir do levantamento de dados foi possível identificar seis diferentes sistemas construtivos (SC) distribuídos em 622,39 metros de perímetro de muralha, com predominância do SC 1, com 33,08\%

e do SC 3, com 49,25\% do perímetro total (Figura 4). Os demais sistemas construtivos, juntos, somam $17,67 \%{ }^{4}$.

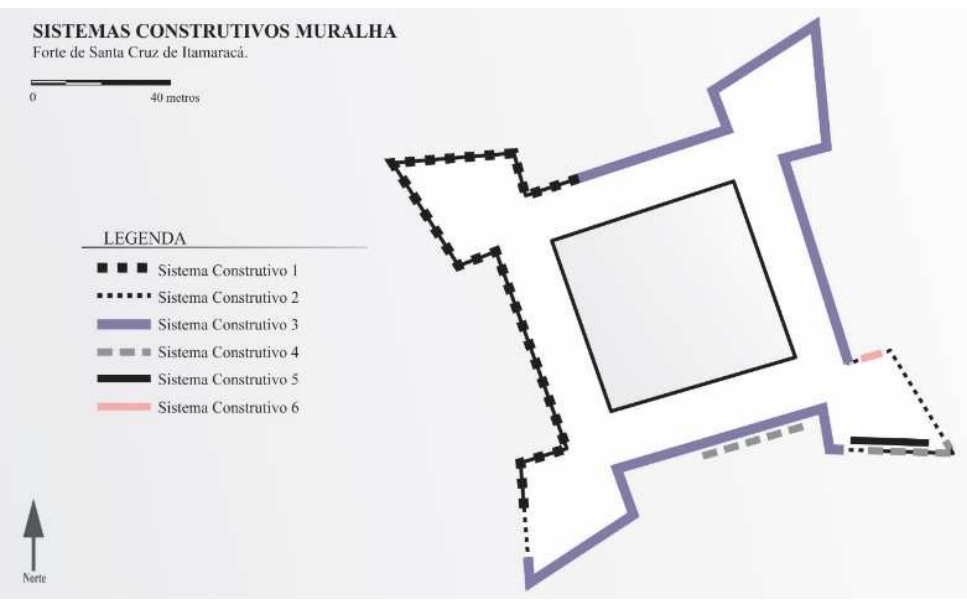

Figura

Espacialização dos Sistemas construtivos (SC) identificados no Forte de Santa Cruz de Itamaracá.

${ }^{4}$ O SC 3 é resultado das obras de reconstrução da fortificação realizadas em 1972. 
Dos seis sistemas construtivos (SC) encontrados na fortificação, cinco deles utilizam rochas na sua composição. O exame macroscópico das rochas, identificou que todas as cinco são muito bem selecionadas, com grãos no tamanho areia fina ou silte (que não podem ser percebidos nem com auxílio de lupa) (Figura 5). Foi identificada a presença de carapaças em três delas - SC 1, SC 4 e SC 6; e há cavidades na rocha, no SC 1, SC 2e SC 6. Verificou-se, ainda, que todas as rochas reagiram ao Ácido clorídrico ( $\mathrm{HCl}$ concentração de 10\%) liberando $\mathrm{CO} 2$ moderadamente por um longo espaço de tempo, exceto a rocha do SC 2 que liberou $\mathrm{CO} 2$ abundantemente por um longo espaço de tempo.

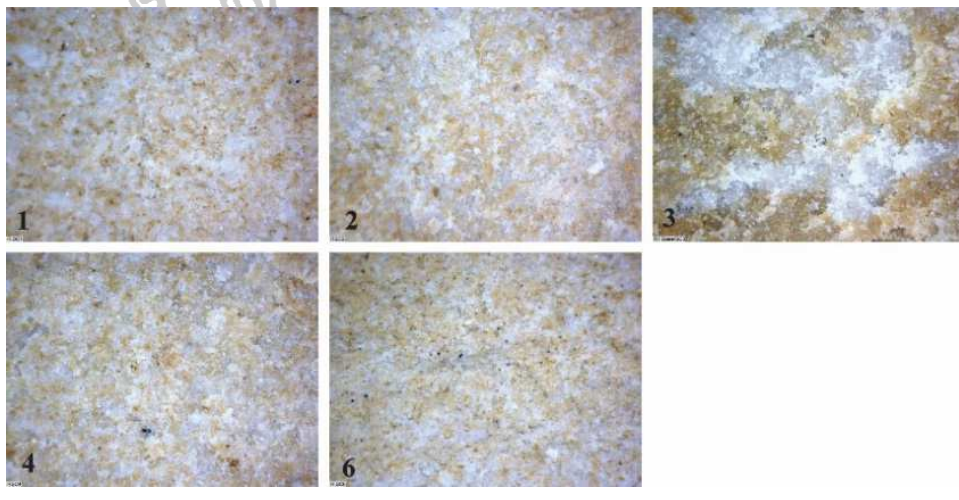

Figura 5. Tipos de rocha do Forte de Santa Cruz de Itamaracá. Rocha 1 (SC1); Rocha 2 (SC2); Rocha 3 (SC3); Rocha 4 (SC4); e Rocha 6 (SC6). Imagens extraídas com Microscópio Digital portátil Dino-Lite PLUS, com aumento de $55 x$.

A análise de Fluorescência de Raio-X permitiu identificar que todas as rochas apresentam elevadas quantidades de Cálcio, com pequena quantidade de Silício, Alumínio e Ferro e traços de Potássio (Gráfico 1). Com destaque para a rocha do SC 6 que apresentou uma pequena variação quantitativa quando comparada às 
demais: a quantidade de Cálcio é ligeiramente menor e o Silício, ligeiramente maior.

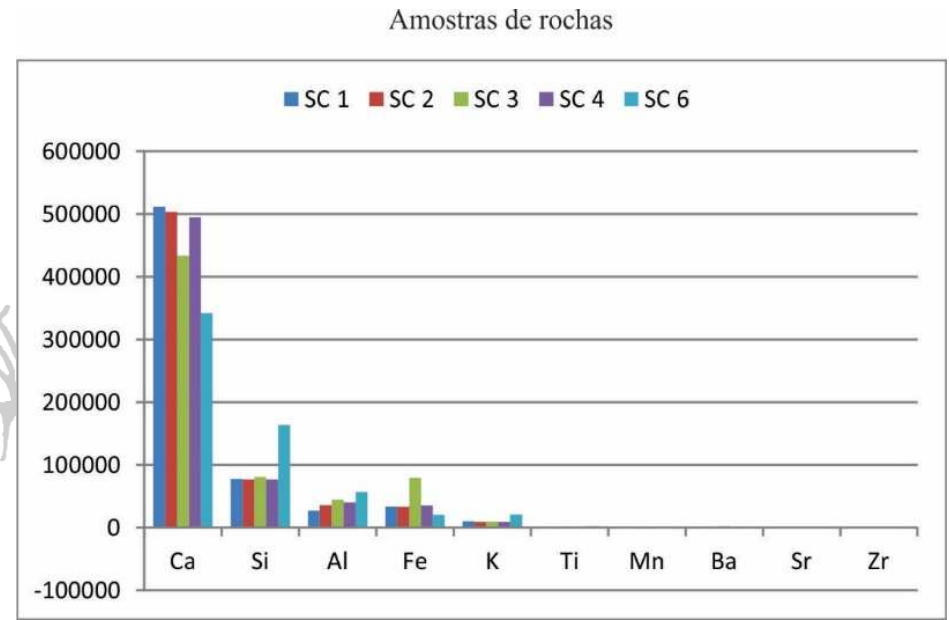

Gráfico 1. Resultados da análise de Fluorescência de Raio-X realizada nos tipos de rocha utilizados no Forte de Santa Cruz de Itamaracá.

Considerando em todas as rochas a elevada quantidade de Cálcio e pequena quantidade de Silício, Alumínio e Ferro pode-se sugerir que as rochas utilizadas em todos os sistemas construtivos do Forte de Santa Cruz de Itamaracá são: Calcário.

Foi ainda realizada Difração de Raio-X (DRX) para as rochas do SC 3 e SC 4 e complementar os resultados obtidos com a FRX. Os resultados obtidos para a rocha do SC 4 mostrou grande quantidade de Dolomita $\left(\mathrm{CaCO}_{3} \cdot \mathrm{MgCO}_{3}\right)$ e Ankerita $\left(\mathrm{Ca}_{2} \mathrm{MgFe}\left(\mathrm{CO}_{3}\right)_{4}\right.$ e pequena quantidade de quartzo $\left(\mathrm{SiO}_{2}\right)$. Segundo Sampaio e Almeida, esses elementos são aqueles constituintes dos calcários e/ou dolomitos. Segundo o "Diagnóstico Ambiental do Litoral Norte", a Formação Gramame apresenta duas fáceis, uma fosfática e uma calcária. A fácie calcária é composta por 
arenito calcífero, calcários arenosos e culminam, no topo, com calcário dolomítico e margoso, muito fossilífero. Por sua vez, a rocha do SC 3 também apresentou o mesmo resultado: grande quantidade de Dolomita $\left(\mathrm{CaCO}_{3} \cdot \mathrm{MgCO}_{3}\right)$ e Ankerita $\left(\mathrm{Ca}_{2} \mathrm{MgFe}\left(\mathrm{CO}_{3}\right)_{4}\right.$ e pequena quantidade de quartzo $\left(\mathrm{SiO}_{2}\right)$, sugerindo tratar-se também de calcário ou dolomito. Segundo os dados do histórico construtivo do Forte, as rochas utilizadas em reforma realizada em 1973 ou foram rochas reutilizadas ou rochas trazidas da Paraíba. Devemos lembrar que a Formação Gramame tem origem no rio de mesmo nome, localizado na Paraíba. Os resultados do DRX reforçam a hipótese de que as rochas utilizadas na construção e nas reformas do Forte de Santa Cruz de Itamaracá são rochas calcárias.

\section{Forte do Brum. 1654}

O Forte do Brum, localizado no bairro do Recife, região central da cidade, foi construído pelos colonizadores portugueses a partir de 1654, sobre o forte holandês de mesmo nome. O Forte foi construído na entrada do porto do Recife, num istmo banhado a leste pelas águas do mar e a oeste, pelo rio Beberibe.

\section{Dados históricos}

Em 1654 os portugueses conquistaram o Forte do Brum, construído pelos holandeses, que por sua vez já foi construído sobre as estruturas do inacabado Forte português, Forte Diogo Paes (Figura 6). Em cartas de 1672 e 1677, João Fernandes Vieira dá notícias ao Rei de que as obras de pedra e cal do Forte do Brum continuavam em andamento (A.H.U., PE, Caixa 6, p. 151 e A.H.U., PE, Caixa 6, p. 
232). Em 1702, Luís Francisco Pimentel escreveu ao Rei dando notícias de que o Forte do Brum precisava de reforço, obras que foram finalizadas em 1707 (A.H.U., PE, Caixa 11, fls. 213-215) (A.H.U., PE, Caixa 12, p. 33-35). Desde 1987 o Forte do Brum foi restaurado e passou a funcionar como Museu Militar (Menezes. 1986:

p. 100-102).

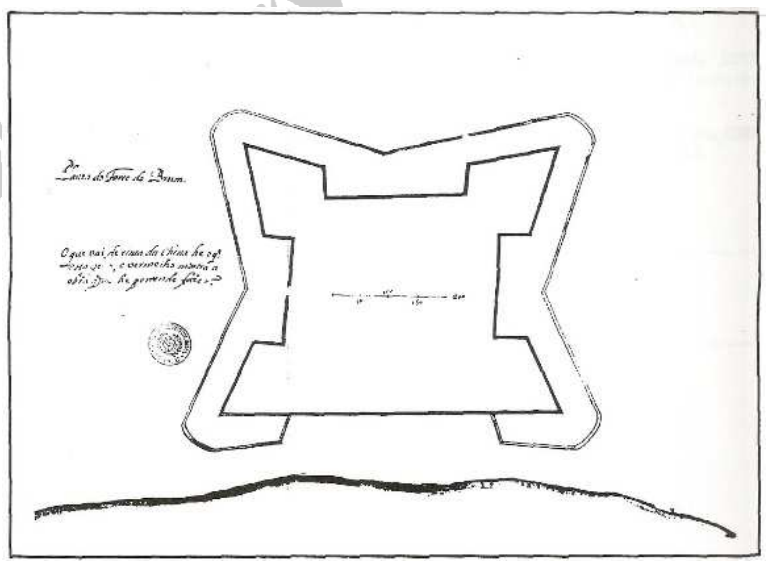

Figura 6. Planta do Forte do Brum, após a capitulação dos holandeses. Fonte: MENEZES. 1986. p. 102.

\section{Configuração Geométrica}

O Forte do Brum é uma fortificação do tipo Fortificação Moderna, abaluartada, incluída na tipologia de Castelo ou Cidadela, segundo Scamozzi, e de Forte quadrantal, segundo Goldman. Apresenta planta com formato de/polígono quadrangular. Os principais itens que compõe a fortificação são: o reparo composto de baluarte, com suas faces e flancos, e cortina. Ao longo de todo o perímetro do terrapleno há parapeito em alvenaria com canhoneiras. Também conta com obras externas como fosso. Sua muralha é inclinada, apresentando caimento médio de $77,19^{\circ}$. Ao longo de toda a muralha, há um cordão em pedra que sinaliza o fim da 
muralha e início do parapeito. Grosso modo, a fortificação mede 109 metros de comprimento, 82 metros de largura e 6 metros de altura, do solo atual até o cordão.

Suas dimensões e proporções estão apresentadas nas tabelas 3 e 4 e Figura 7:

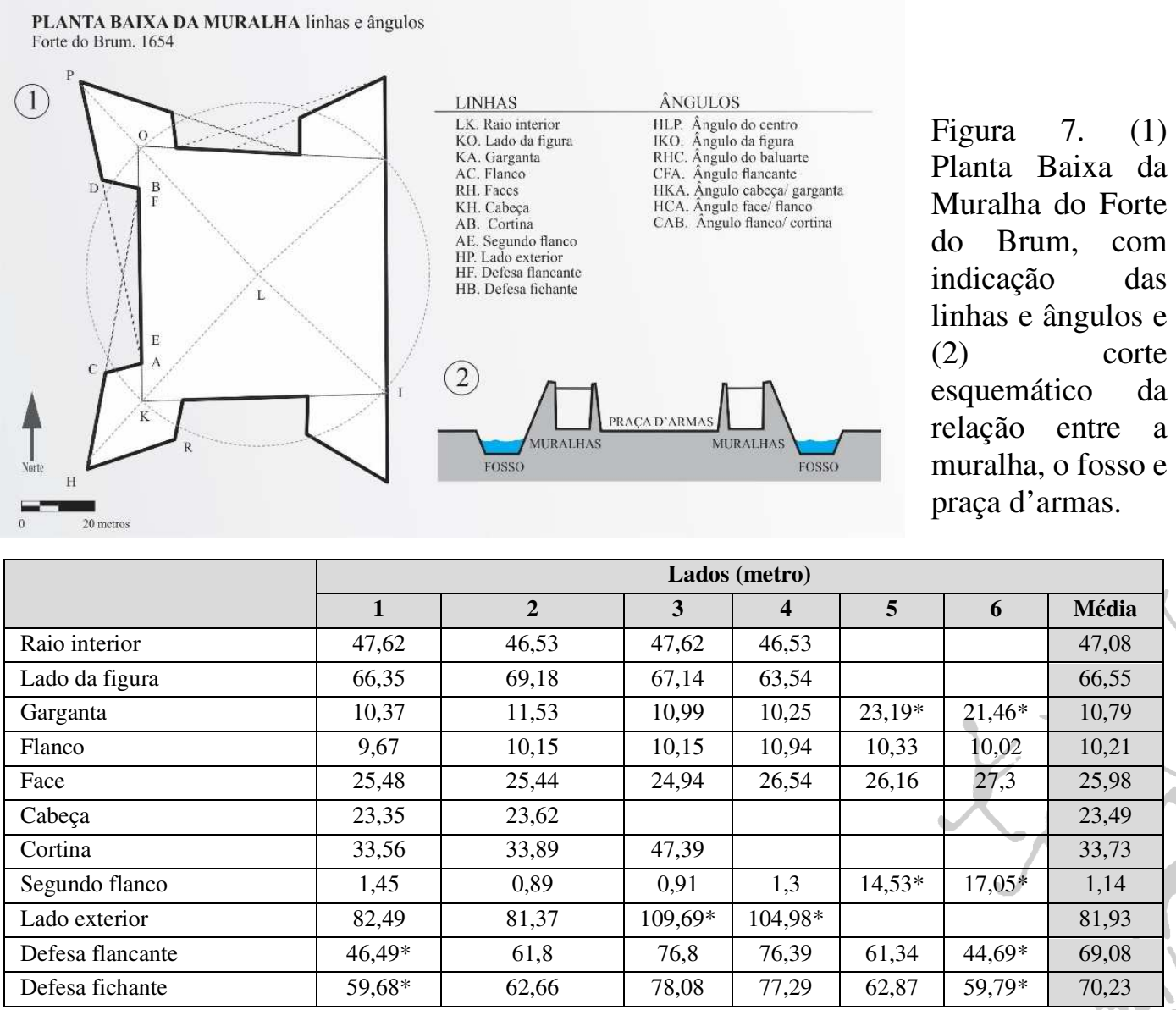

* Esses valores são referentes aos meios baluartes, que são diferentes dos baluartes, por isso não estão sendo considerados no cálculo das respectivas médias.

Tabela 3. Medidas lineares aferidas em campo por levantamento topográfico, com utilização de Estação Total. Forte do Brum. 


\begin{tabular}{|l|c|c|c|c|c|c|c|}
\hline & Ângulo 1 & Ângulo 2 & Ângulo 3 & Ângulo 4 & Ângulo 5 & Ângulo 6 & Média \\
\hline Ângulo do centro & $84,0^{\circ}$ & $90,9^{\circ}$ & $94,6^{\circ}$ & $89,6^{\circ}$ & & & $90,0^{\circ}$ \\
\hline Ângulo da figura & $93,4^{\circ}$ & $85,9^{\circ}$ & $89,2^{\circ}$ & $91,36^{\circ}$ & & & $90,0^{\circ}$ \\
\hline Ângulo baluarte & $65,0^{\circ}$ & $58,9^{\circ}$ & $61,3^{\circ}$ & $59,2^{\circ}$ & & & $61,1^{\circ}$ \\
\hline Ângulo flancante & $28,4^{\circ *}$ & $32,4^{\circ *}$ & $17,0^{\circ}$ & 11,45 & $11,4^{\circ}$ & $15,5^{\circ}$ & $13,8^{\circ}$ \\
\hline Ângulo cabeça/garganta & $134,9^{\circ}$ & $139,1^{\circ}$ & $140,2^{\circ}$ & $130,5^{\circ}$ & & & $136,2^{\circ}$ \\
\hline Ângulo face/flanco & $115,1^{\circ}$ & $120,3^{\circ}$ & $119,2^{\circ}$ & $115,2^{\circ}$ & $115,4^{\circ}$ & $115,2^{\circ}$ & $116,7^{\circ}$ \\
\hline Ângulo flanco/cortina & $103,8^{\circ}$ & $103,6^{\circ}$ & $99,9^{\circ}$ & $86,8^{\circ}$ & $86,7^{\circ}$ & $103,3^{\circ}$ & $97,4^{\circ}$ \\
\hline
\end{tabular}

* Esses valores são referentes aos meios baluartes, que são diferentes dos baluartes, por isso não estão sendo considerados no cálculo das respectivas médias.

Tabela 4. Medidas angulares aferidas em campo por levantamento topográfico, com utilização de Estação Total. Forte do Brum.

\section{Escolha dos materiais construtivos}

O Forte do Brum está construído em alvenaria de rocha com argamassa de barro e cal. Chama-se atenção para os reparos nas áreas das cortinas norte e sul, pois são vazios, ocupados por ambientes interno de uso das atividades do Museu. A partir do levantamento de dados físicos das alvenarias de rocha foi possível identificar cinco diferentes sistemas construtivos (SC) ao longo dos 441,71 metros de reparo (Figura 8). Deve-se registrar que parte do reparo está revestida com reboco e pintada, não sendo possível visualizar o sistema construtivo (este trecho representa 23,9\% do perímetro total). Os sistemas construtivos predominantes, SC 1 e SC 4, somam, respectivamente, 117,04 metros $(26,50 \%)$ e 124,26 metros $(28,14 \%)$ do perímetro. Os demais sistemas construtivos, juntos, somam $21,46 \%$. 


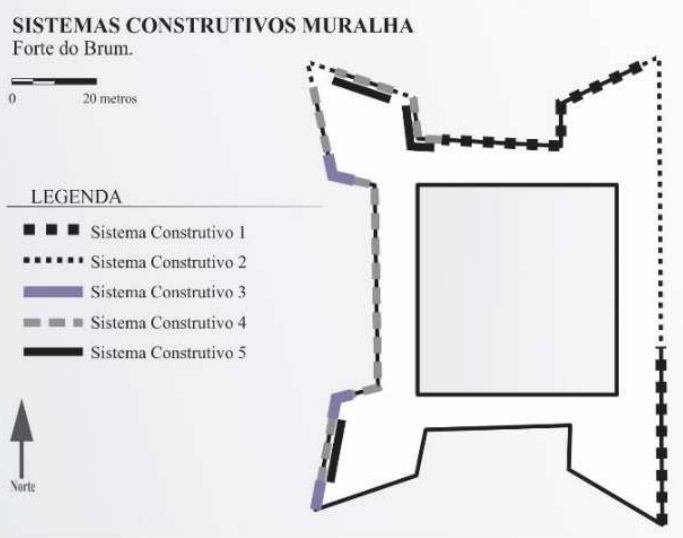

Figura 8. Espacialização dos Sistemas construtivos identificados no Forte do Brum.

O exame macroscópico das rochas evidenciou que estas são muito bem selecionadas, com grãos tamanho areia média e fina (que podem ser percebidos sem auxílio de lupa), sub-arredondados, de baixa esfericidade, na cor creme (Figura 9). Diferentemente das demais, a rocha do SC 2 apresenta 25\% de impurezas em um trecho da rocha. Todas as rochas reagiram ao Ácido clorídrico ( $\mathrm{HCl}$ concentração de $10 \%)$ liberando $\mathrm{CO} 2$ abundantemente por um curto espaço de tempo. 

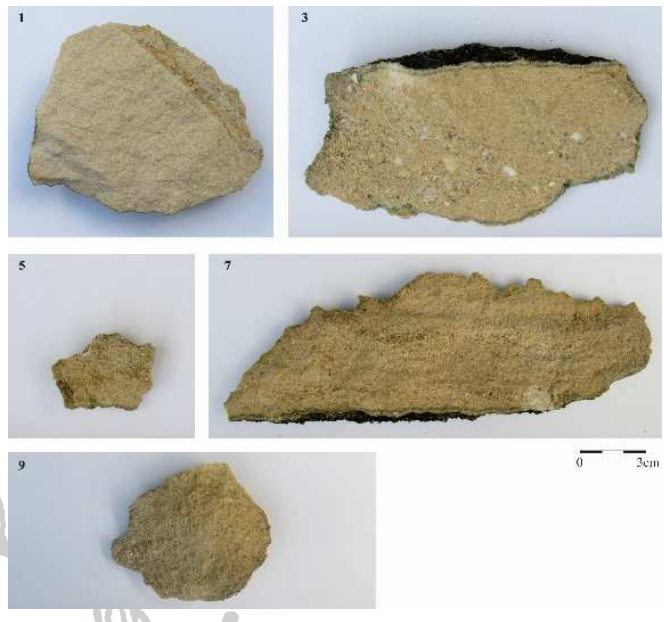

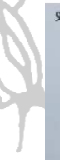

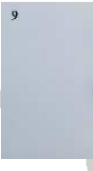

Figura 9. Tipos de rocha do Forte do Brum. Rocha 1 (SC 1), Rocha 3 (SC 2), Rocha 5 (SC 3), Rocha 7 (SC 4) e Rocha 9 (SC 5).

A análise de Fluorescência de Raio-X permitiu identificar qualitativa e quantitativamente os elementos químicos que compõe as rochas identificadas. Os resultados evidenciaram que todas as rochas apresentam elevadas quantidades de Cálcio e Silício com traços de Alumínio, Ferro e Potássio (Gráfico 2). Considerando a elevada quantidade de Silício presente nas rochas, pode-se sugerir que as rochas utilizadas na construção e nas reformas do Forte do Brum foram arenitos quartzosos. 
Amostras de rochas

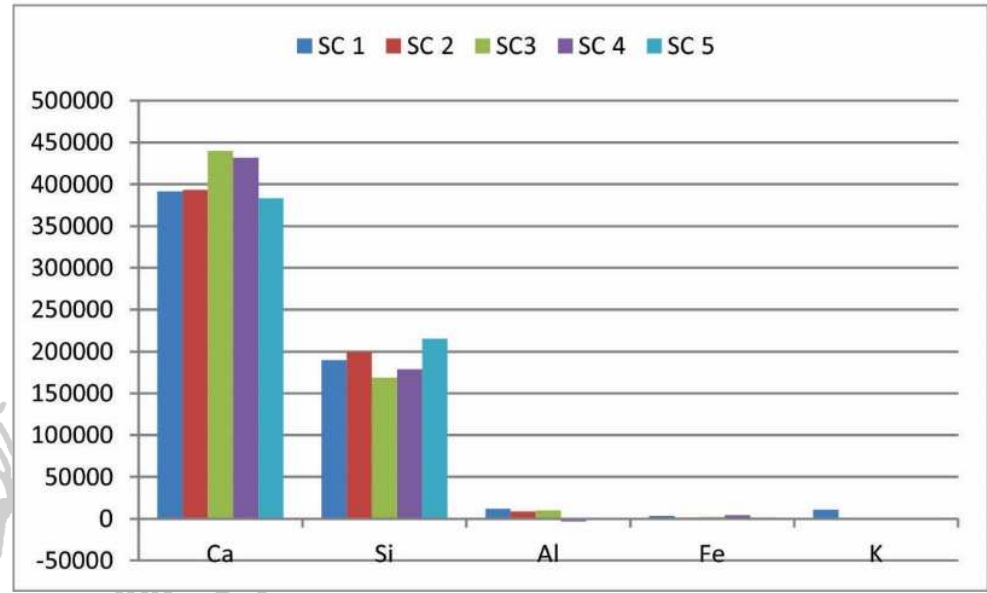

Gráfico 2. Resultados da análise de Fluorescência de Raio-X realizada nos tipos de rocha utilizados no Forte Brum. A Rocha 1 (SC 1), Rocha 3 (SC 2), Rocha 5 ( $\mathrm{SC} 3$ ), Rocha 7 (SC 4) e Rocha 9 (SC 5).

\section{Forte de São Tiago das Cinco Pontas. 1654}

O Forte de São Tiago das Cinco Pontas, localizado no bairro de São José, no centro do Recife, foi construído pelos colonizadores portugueses a partir de 1654, sobre $\mathrm{\alpha}$ Forte holandês Frederich Heinrich.

\section{Dados históricos}

O primitivo forte holandês tinha formato de polígono regular pentagonal, com cinco baluartes (Figura 10), mas o forte português foi construído com formato de polígono quadrangular, em alvenaria de pedra e cal, pelo Engenheiro Militar Francisco Correia Pinto. 


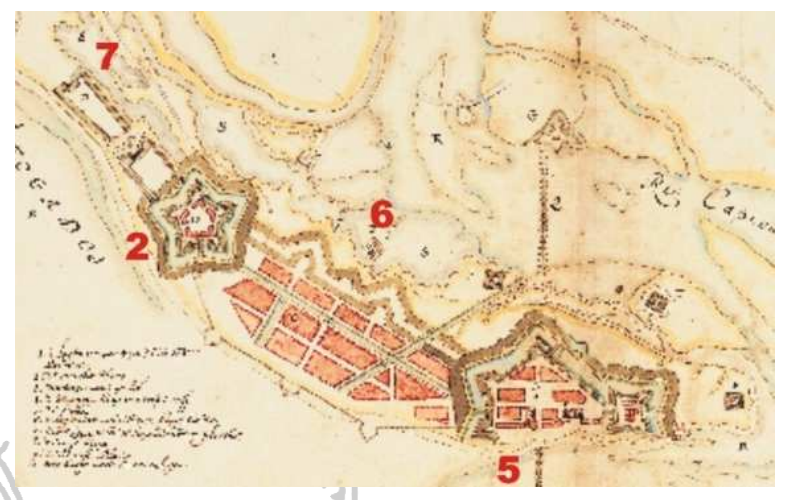

Figura 10. Ilustração denominada "CAERTE VANDE HAVEN VAN PHARNAMBOCQUE”, de 1639. Legenda: 2. Forte das Cinco Pontas. 5. Forte Ernesto. 6. Reduto da Boa Vista. 7. Forte Emilia.

Em 1677, João Fernandes Vieira dá notícias de que a obra do Forte de São Tiago das Cinco Pontas estava finalizada (A.H.U., PE, Caixa 6, p. 232). Nos séculos XVIII, XIX e XX há notícias de que a fortificação foi objeto de obras (A.H.U., PE,

Caixa 11, fls. 213-215) (A.H.U., PE, Caixa 12, p. 33-35). Em 1982, após restauração, foi aberto ao público como sede do Museu da Cidade do Recife (Menezes. 1986: p. 104 e 105).

\section{Configuração Geométrica}

O Forte São Tiago das Cinco Pontas é uma fortificação do tipo Fortificação Moderna, abaluartada, incluída na tipologia de Castelo ou Cidadela, segundo Scamozzi, e de Forte quadrantal, segundo Goldman. Apresenta planta com formato de polígono retangular (Figura 11). Os principais itens que compõe a fortificação são: reparo contendo baluarte, com suas faces e flancos, e cortina. Sobre o terrapleno, ao longo de todo perímetro da fortificação há parapeito em alvenaria, com canhoneiras. A fortificação ainda conta com fosso. Suas dimensões e 
proporções estão apresentadas nas tabelas 5 e 6 apresentadas abaixo. Sua muralha é inclinada, apresentando caimento médio de $76,53^{\circ}$. Ao longo de toda a muralha, há um cordão em pedra que sinaliza o fim da muralha e início do parapeito. Grosso modo, a fortificação mede 83 metros de comprimento, 76 metros de largura e 3,80 metros de altura, do solo atual até o cordão em pedra.

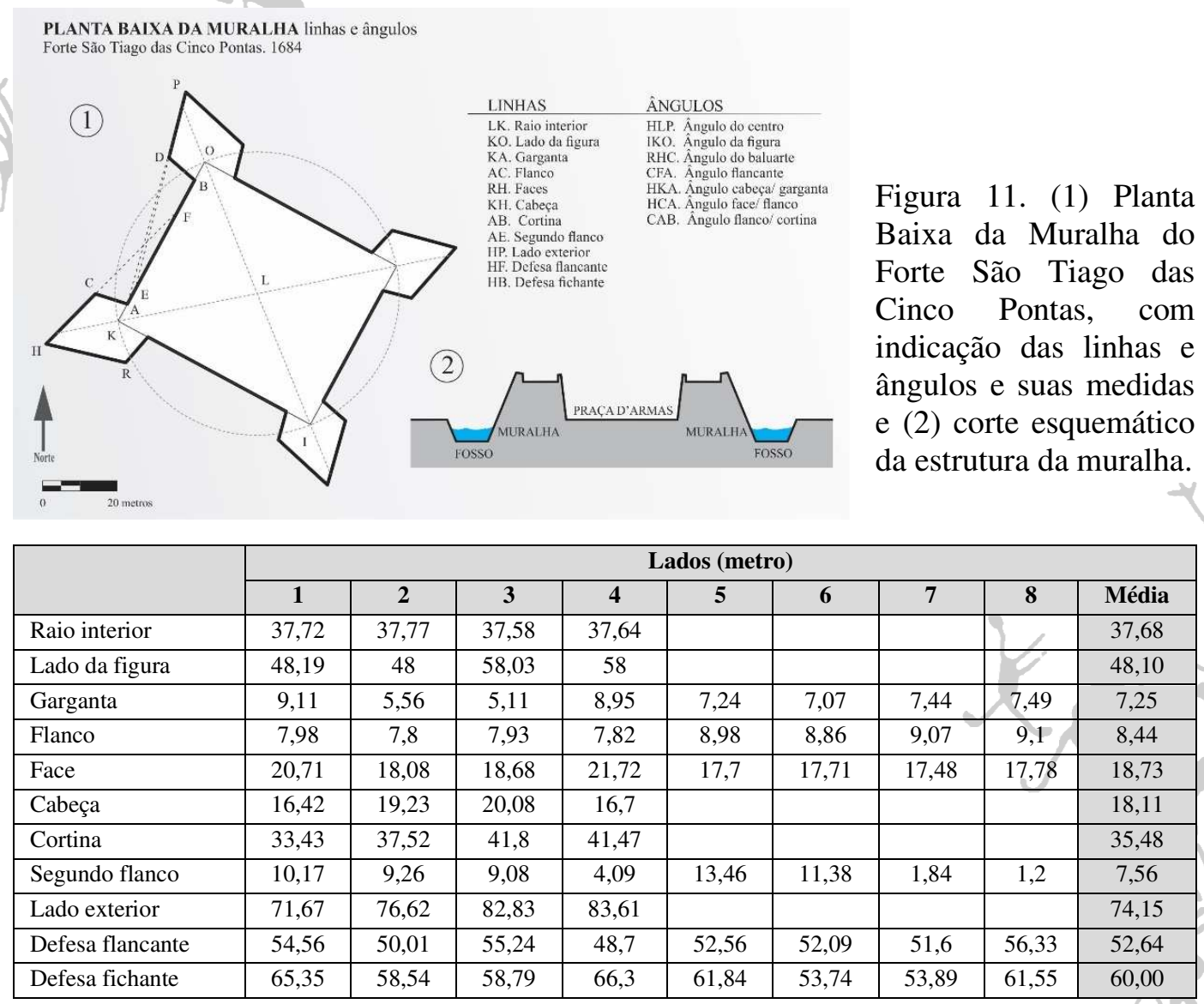

Tabela 5. Medidas lineares aferidas em campo por levantamento topográfico, com utilização de Estação Total. Forte São Tiago das Cinco Pontas. 


\begin{tabular}{|l|c|c|c|c|c|c|c|c|c|}
\hline & $\begin{array}{c}\text { Ângulo } \\
\mathbf{1}\end{array}$ & $\begin{array}{c}\text { Ângulo } \\
\mathbf{2}\end{array}$ & $\begin{array}{c}\text { Ângulo } \\
\mathbf{3}\end{array}$ & $\begin{array}{c}\text { Ângulo } \\
\mathbf{4}\end{array}$ & $\begin{array}{c}\text { Ângulo } \\
\mathbf{5}\end{array}$ & $\begin{array}{c}\text { Ângulo } \\
\mathbf{6}\end{array}$ & $\begin{array}{c}\text { Ângulo } \\
\mathbf{7}\end{array}$ & $\begin{array}{c}\text { Ângulo } \\
\mathbf{8}\end{array}$ & Média \\
\hline Ângulo do centro & $100,4^{\circ}$ & $100,8^{\circ}$ & $79,1^{\circ}$ & $79,5^{\circ}$ & & & & & $100,6^{\circ}$ \\
\hline Ângulo da figura & $89,9^{\circ}$ & $90,2^{\circ}$ & $89,9^{\circ}$ & $89,9^{\circ}$ & & & & & $90,03^{\circ}$ \\
\hline Ângulo baluarte & $64,1^{\circ}$ & $63,1^{\circ}$ & $58,5^{\circ}$ & $61,6^{\circ}$ & & & & & $61,8^{\circ}$ \\
\hline Ângulo flancante & $14,3^{\circ}$ & $13,1^{\circ}$ & $16,1^{\circ}$ & $14,0^{\circ}$ & $15,1^{\circ}$ & $14,2^{\circ}$ & $12,8^{\circ}$ & $12,7^{\circ}$ & $14,0^{\circ}$ \\
\hline $\begin{array}{l}\text { Ângulo } \\
\text { cabeça/garganta }\end{array}$ & $133,5^{\circ}$ & $136,4^{\circ}$ & $135,5^{\circ}$ & $134,5^{\circ}$ & $135,6^{\circ}$ & $134,1^{\circ}$ & $136,1^{\circ}$ & $134^{\circ}$ & $135^{\circ}$ \\
\hline $\begin{array}{l}\text { Angulo } \\
\text { face/flanco }\end{array}$ & $116,9^{\circ}$ & $117,6^{\circ}$ & $116,8^{\circ}$ & $115,6^{\circ}$ & $117,1^{\circ}$ & $116,5^{\circ}$ & $119^{\circ}$ & $116,5^{\circ}$ & $117,0^{\circ}$ \\
\hline $\begin{array}{l}\text { Angulo } \\
\text { flanco/cortina }\end{array}$ & $104,6^{\circ}$ & $102,4^{\circ}$ & $100,7^{\circ}$ & $102,5^{\circ}$ & $102,6^{\circ}$ & $102,7^{\circ}$ & $103,8^{\circ}$ & $103,9^{\circ}$ & $102,9^{\circ}$ \\
\hline
\end{tabular}

Tabela 6. Medidas angulares aferidas em campo por levantamento topográfico, com utilização de Estação Total. Forte São Tiago das Cinco Pontas.

\section{Escolha dos materiais construtivos}

O Forte São Tiago das Cinco Pontas está construído em alvenaria de pedra com argamassa de barro e cal. Em todos os cantos da fortificação, verifica-se uma alvenaria de pedra aparente (SC1), composta por rochas talhadas de formato retangular, com tratamento de superfície (Figura 12). O exame macroscópico revelou uma rocha muito bem selecionada, com grãos tamanho areia média (que podem ser percebidos sem auxílio de lupa), sub-anguloso, de baixa esfericidade, na cor creme. Verificou-se, ainda, a presença de impurezas, conchas e fragmentos de conchas, num percentual que varia de $1 \%$ a 50\%. A rocha reagiu ao Ácido clorídrico ( $\mathrm{HCl}$ concentração de $10 \%$ ) liberando $\mathrm{CO} 2$, abundantemente por um longo tempo. 

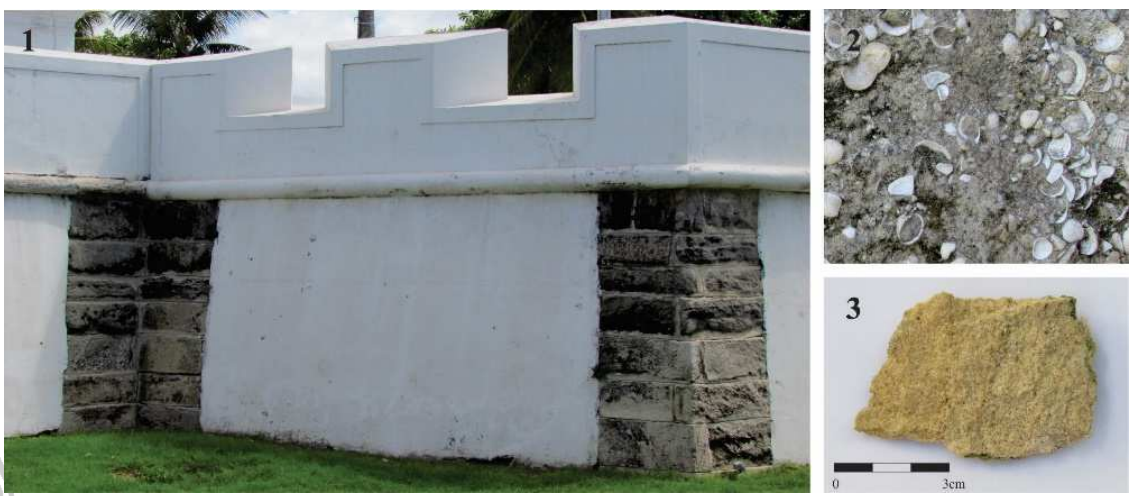

Figura 12. 1.

Rocha do

Forte São

Tiago das

Cinco Pontas;

2. Impurezas;

e 3 Rocha 1

(SC 1).

A análise de Fluorescência de Raio-X evidenciou uma elevada quantidade de Cálcio e Silício com traços de Alumínio e vestígios de outros elementos, como o Ferro (Gráfico 3). Considerando a elevada quantidade de Silício presente na rocha, sugere-se que a rocha utilizada não foi o Calcário, pois este mineral é considerado uma impureza quando presente em rochas calcárias. Infere-se, portanto, que a rocha utilizada foi o arenito quartzoso.

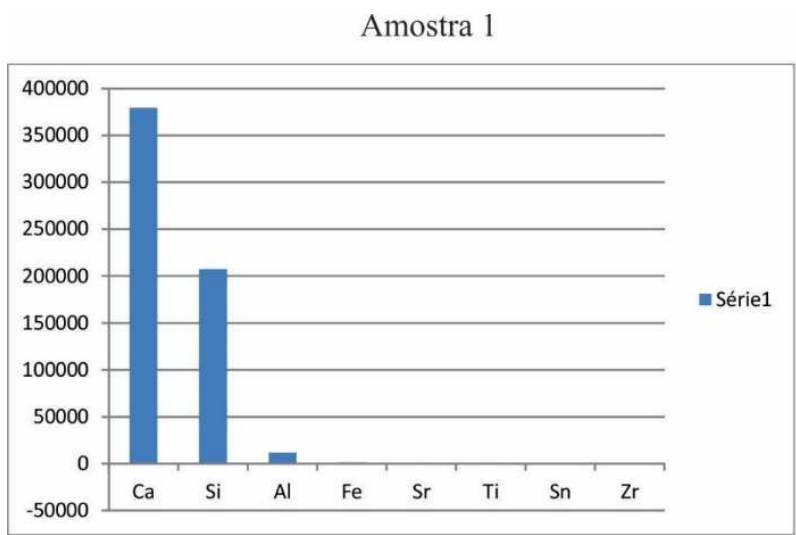

Gráfico 3. Resultados da análise de Fluorescência de Raio-X realizada nos tipos de rocha utilizados no Forte São Tiago das Cinco Pontas. 


\section{Forte de Santo Inácio de Loyola de Tamandaré. 1654}

O Forte de Santo Inácio de Loyola de Tamandaré foi construído pelos colonizadores portugueses a partir de 1654. Está localizado no município de Tamandaré, no litoral sul do Estado de Pernambuco, distante cerca de 80km do Recife. O Forte foi construído numa planície costeira, em área de restinga.

\section{Dados históricos}

Em 1654, João Fernandes Vieira manda construir um forte de formato quadrado com quatro baluartes. Em 1677, há a notícias de que a obra da Fortaleza de Santo Inácio de Loyola de Tamandaré estava finalizada (A.H.U., PE, Caixa 6, p. 232.). As obras contaram com o apoio dos moradores locais em material de construção, mão-de-obra, carro e animais. Há notícias de que a fortificação foi construída em alvenaria de rocha, com rochas trazidas por via marítima de Porto Calvo, em Alagoas. Ainda no século XVII, foi objeto e reforma. Foi utilizado como prisão política para prisioneiros em trânsito. Durante a segunda guerra mundial, até 1945, foi quartel para as tropas do Exército do Brasil. Desde 1978, está sob á guarda da Capitania dos Portos (Ministério da Marinha) e abriga um farol (Menezes. 1986: p. 103-104).

\section{Configuração Geométrica}

O Forte Santo Inácio de Loyola de Tamandaré é uma fortificação do tipo Fortificação Moderna, abaluartada, incluída na tipologia de Castelo ou Cidadela, segundo Scamozzi, e Forte quadrantal, segundo Goldman. Apresenta planta com 
formato de polígono quadrangular. Os principais itens que compõe a fortificação são: reparo contendo baluarte, com suas faces e flancos, e cortina. Sobre o terrapleno, ao longo de todo perímetro da fortificação há parapeito em alvenaria, com canhoneiras (Figura 13). A fortificação ainda conta vestígios do fosso como obras externa.

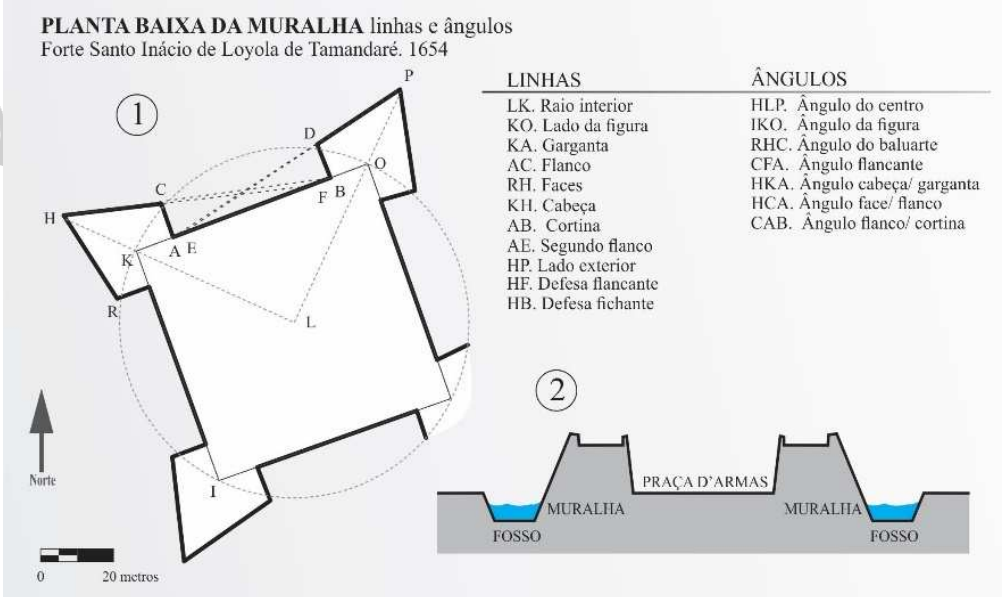

Figura 13. Planta Baixa da Muralha do Forte Santo Inácio de Loyola de Tamandaré, com indicação das linhas e ângulos e (2) corte esquemático da estrutura da muralha.

Suas dimensões e proporções estão detalhadas nas tabelas 7 e 8, abaixo. Sua muralha é inclinada, apresentando caimento médio de $78,03^{\circ}$. Ao longo de toda a muralha, há um cordão em pedra que sinaliza o fim da muralha e início do parapeito, também em pedra. Grosso modo, a fortificação mede 98 metros de comprimento, 100 metros de largura e 3,85 metros de altura, do solo atual até o cordão em pedra.

\begin{tabular}{|l|c|c|c|c|c|c|c|c|c|}
\hline & \multicolumn{9}{|c|}{ Lados (metro) } \\
\cline { 2 - 11 } & $\mathbf{1}$ & $\mathbf{2}$ & $\mathbf{3}$ & $\mathbf{4}$ & $\mathbf{5}$ & $\mathbf{6}$ & $\mathbf{7}$ & $\mathbf{8}$ & Média \\
\hline Raio interior & 47,84 & 47,49 & 47,6 & 47,85 & & & & & 47,70 \\
\hline Lado da figura & 67,7 & 66,69 & 67,34 & 68,09 & & & & & 67,46 \\
\hline Garganta & 10,58 & 10,9 & 10,75 & 10,38 & 11,12 & 10,55 & 9,89 & 11,21 & 10,67 \\
\hline
\end{tabular}




\begin{tabular}{|l|c|c|c|c|c|c|c|c|c|}
\hline Flanco & 9,82 & 9,79 & 9,33 & 9,67 & 9,76 & 9,87 & $9,32^{*}$ & $7,86^{*}$ & 9,71 \\
\hline Face & 26,95 & 27,1 & 27,25 & 27,97 & 28,85 & 28,66 & $27,01^{*}$ & $28,98^{*}$ & 27,80 \\
\hline Cabeça & 23,98 & 22,15 & 22,18 & $22,42^{*}$ & & & & & 22,77 \\
\hline Cortina & 46,04 & 45,75 & 46,32 & 46,29 & & & & & 46,10 \\
\hline Segundo flanco & 6,53 & 2,35 & 4,57 & 5,19 & 0 & 10,91 & $21,1^{*}$ & $4,86^{*}$ & 6,94 \\
\hline Lado exterior & 98,37 & 100,1 & $99,42^{*}$ & $100,25^{*}$ & & & & & 99,24 \\
\hline Defesa flancante & 67,42 & 68,6 & 71,83 & 74,39 & 71,15 & 65,24 & $53,32^{*}$ & $70,37^{*}$ & 69,77 \\
\hline Defesa fichante & 73,78 & 73,67 & 75,61 & 75,81 & 74,14 & 74,63 & $75,13^{*}$ & $73,73^{*}$ & 74,61 \\
\hline
\end{tabular}

* Esses valores são hipotéticos. São referentes ao baluarte que não existe mais, por isso não estão sendo considerados no cálculo das respectivas médias.

Tabela 7. Medidas lineares aferidas em campo por levantamento topográfico, com utilização de Estação Total. Forte Santo Inácio de Loyola de Tamandaré.

\begin{tabular}{|c|c|c|c|c|c|c|c|c|c|}
\hline & $\begin{array}{c}\text { Ângulo } \\
1\end{array}$ & $\begin{array}{c}\text { Ângulo } \\
2\end{array}$ & $\begin{array}{c}\text { Ângulo } \\
\mathbf{3}\end{array}$ & $\begin{array}{c}\text { Ângulo } \\
4\end{array}$ & $\begin{array}{c}\text { Ângulo } \\
5\end{array}$ & $\begin{array}{c}\hat{\text { Ângulo }} \\
\mathbf{6}\end{array}$ & $\begin{array}{c}\text { Ângulo } \\
7\end{array}$ & $\begin{array}{c}\hat{\text { Ângulo }} \\
\mathbf{8}\end{array}$ & Média \\
\hline Ângulo do centro & $91,0^{\circ}$ & $90,4^{\circ}$ & $88,7^{\circ}$ & $89,7^{\circ}$ & & & & & $90,0^{\circ}$ \\
\hline Ângulo da figura & $88,8^{\circ}$ & $90,8^{\circ}$ & $90,3^{\circ}$ & $89,9^{\circ}$ & & & & & $90,0^{\circ}$ \\
\hline $\begin{array}{l}\text { Ângulo do } \\
\text { baluarte }\end{array}$ & $63,9^{\circ}$ & $64,9^{\circ}$ & $61,3^{\circ}$ & $59,6^{\circ *}$ & & & & & $63,4^{\circ}$ \\
\hline Ângulo flancante & $13,8^{\circ}$ & $12,7^{\circ}$ & $13,3^{\circ}$ & $12,9^{\circ}$ & $15,6^{\circ}$ & $11,1^{\circ}$ & $17,3^{\circ * *}$ & $12,9^{\circ *}$ & $13,2^{\circ}$ \\
\hline $\begin{array}{l}\text { Ângulo } \\
\text { cabeça/garganta }\end{array}$ & $132,7^{\circ}$ & $136,8^{\circ}$ & $133,3^{\circ}$ & $135,8^{\circ}$ & $134,1^{\circ}$ & $136,9^{\circ}$ & $134,7^{\circ *}$ & $135,3^{\circ *}$ & $134,9^{\circ}$ \\
\hline $\begin{array}{l}\text { Ângulo } \\
\text { face/flanco }\end{array}$ & $102,5^{\circ}$ & $102,2^{\circ}$ & $104,2^{\circ}$ & $103,5^{\circ}$ & $97,3^{\circ}$ & $101,5^{\circ}$ & $96,2^{\circ *}$ & $106,6^{\circ *}$ & $101,9^{\circ}$ \\
\hline $\begin{array}{l}\text { Ângulo } \\
\text { flanco/cortina }\end{array}$ & $88,7^{\circ}$ & $89,2^{\circ}$ & $88,7^{\circ}$ & $86,1^{\circ}$ & $83,3^{\circ}$ & $89,2^{\circ}$ & $87,8^{\circ *}$ & $90,9^{\circ *}$ & $87,5^{\circ}$ \\
\hline
\end{tabular}

* Esses valores são hipotéticos. São referentes ao baluarte que não existe mais, por isso não estão sendo considerados no cálculo das respectivas médias.

Tabela 8. Medidas angulares aferidas em campo por levantamento topográfico, com utilização de Estação Total. Forte Santo Inácio de Loyola de Tamandaré.

\section{Escolha dos materiais construtivos}

O Forte Santo Inácio de Loyola de Tamandaré está construído em terra e encamisado em alvenaria de pedra com argamassa de barro e cal. É composto por 
rochas aparelhadas, com tratamento de superfície, e formato irregular, mas tendendo a polígonos de tamanhos variados.

\section{Resultados da Classificação Tipológica}

Os aspectos da caracterização física considerados para avaliar as fortificações construídas na Capitania de Pernambuco foram: formato, dimensões e proporções, modelos e inclinação dos muros. Estas são variáveis referentes ao conceito de Configuração Geométrica trabalhado nesta pesquisa. Tipologicamente, as fortificações construídas na colônia brasileira poderiam ser ou Fortificação de Transição ou Fortificação Moderna ${ }^{5}$. A Fortificação de Transição, grosso modo, era formada por muralhas altas, intercaladas por tambores vazios, uma estrutura frágil diante dos canhões de alto calibre em uso desde 1530, em toda a Europa. Uma Fortificação Moderna, por sua vez, era uma estrutura formada por um maciço de terra denominado Reparo, que funcionava como uma gigantesca trincheira, e tinha o objetivo de amortecer o impacto dos projéteis das armas de fogo (Figura 12). As partes exterior e interior do Reparo eram escarpadas, em talude, podendo ou não, serem encamisadas ${ }^{6}$ (Guia de inventário, 2015: p.100).

\footnotetext{
${ }^{5}$ haja vista não haver referências da existência de Fortificação medieval na Capitania.

${ }^{6}$ Encamisar significa revestir a escarpa pelo assentamento uniforme de pedras ou outro material.
} 


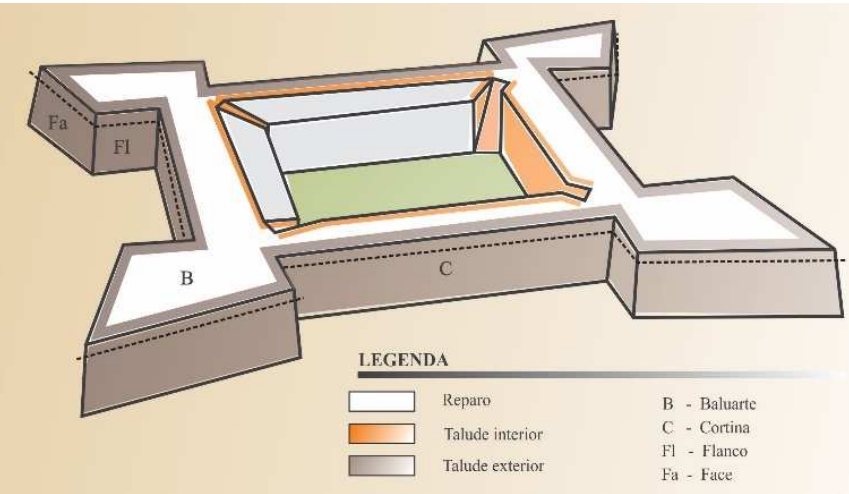

Figura 12. Esquema de uma fortificação moderna, abaluartada, com seus elementos básicos: cortina e baluarte.

No caso das quatro fortificações estudadas, todas construídas após 1654, verificouse que os conteúdos são homólogos àqueles do tipo Moderno, especificamente do modelo abaluartado, que contava com linhas flancantes ${ }^{7}$.

\section{Resultado da Classificação quanto a modelos europeus modernos}

Após a classificação das fortificações estudadas como moderna, foi feita uma nova análise a partir da comparação da Configuração Geométrica dessas fortificações com aquela dos modelos normatizados apresentados nos Tratados usados na pesquisa $^{8}$. Num primeiro momento, foi elaborada uma planta baixa padrão (Figura 13) com indicação do nome e localização de linhas e ângulos.

\footnotetext{
${ }^{7} \mathrm{O}$ baluarte é uma estrutura que se projetava para fora da muralha, permitindo atirar no inimigo. A trajetória dos projetis desenharia uma linha (linhas flancantes) que partiam dos flancos em direção à face do baluarte contíguo. Cada linha seria um canhão e o conjunto de linhas formava uma faixa de defesa. Quanto mais larga a faixa de defesa, maior a capacidade de defesa da fortificação.

${ }^{8}$ Os Tratados utilizados foram: Tratado italiano: "L' Idea della Architettura Universale", Vicenzo Scamozzi, publicado em 1615; e Tratados holandeses: "L'Architectura Militair e Moderne ou Fortification", Matthias Dogen, publicado em 1648; e "La Nouvelle Fortification", Nicolas Goldman, publicado em 1645.
} 

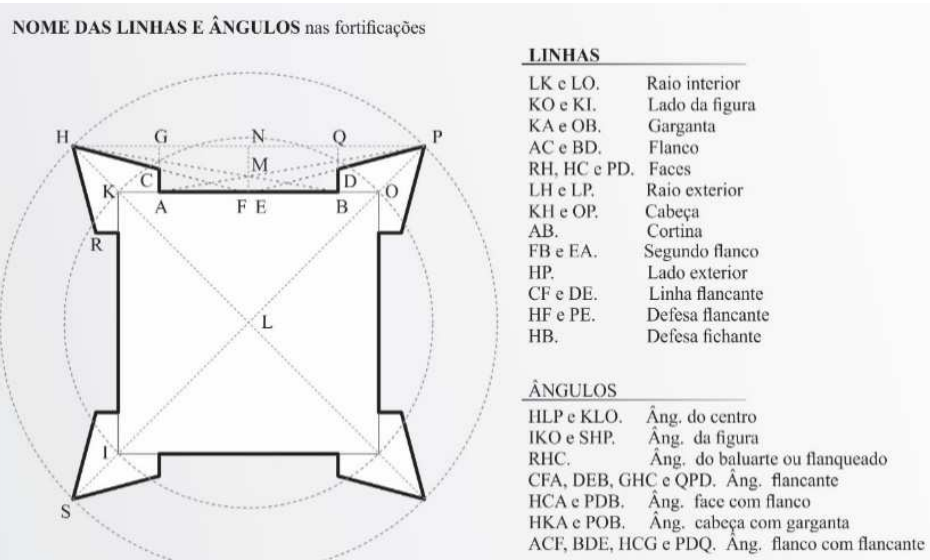

Figura 13. Planta de fortificação genérica com nomes de linhas e ângulos que compõe a sua configuração geométrica.

As quatro fortificações que estão sendo estudadas e os cinco modelos apresentados nos Tratados tiveram suas plantas baixas organizadas nesse padrão, e, ainda, foram desenhadas em escala, no intuito de evidenciar, inclusive, as diferenças de dimensão das fortificações construídas e dos modelos (Figura 14). Observando o quadro-síntese abaixo, vê-se a pequena dimensão das fortificações pernambucanas, em comparação com aquelas dos modelos. Para possibilitar a identificação do modelo, foi realizada uma redução das suas medidas para permitir a comparação com as medidas lineares das fortificações pernambucanas. Foi, ainda, realizada a comparação das medidas angulares. 


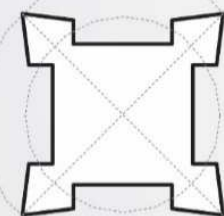

Scamozzi,

Castelo ou Cidadela
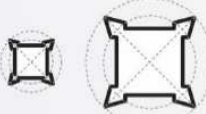

Goldman, Goldman,

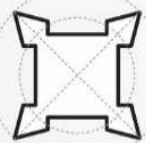

Dogen la. e 2a. maneir

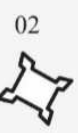

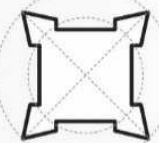

Dogen

3a. maneira

04

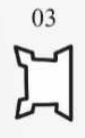

Figura

14.

Quadro-síntese, com plantas baixa dos modelos e das fortificações construídas em Pernambuco, apresentadas na mesma escala.

No caso do Forte de Santa Cruz de Itamaracá, por exemplo, as medidas lineares e angulares estão mais próximas aos valores das medidas do modelo criado por Mathias Dogen, denominado Fortaleza (de formato quadrangular, cujas dimensões e proporções são da $1^{\mathrm{a}}$. e $2^{\mathrm{a}}$. maneira de calcular as medidas das fortificações) (Tabelas 9 e 10).

\begin{tabular}{l|c|ccc:cc}
\hline $\begin{array}{c}\text { Medidas } \\
\text { lineares } \\
\text { (Metro) }\end{array}$ & $\begin{array}{c}\text { Fortificação } \\
\text { Média }\end{array}$ & $\begin{array}{c}\text { Valor teórico } \\
\text { SCAMOZZI } \\
\text { Castelo e } \\
\text { Cidadela }\end{array}$ & $\begin{array}{c}\text { Valor teórico } \\
\text { GOLDMAN } \\
\text { F.Quadrantal }\end{array}$ & $\begin{array}{c}\text { Valor teórico } \\
\text { GOLDMAN } \\
\text { Meio Forte }\end{array}$ & $\begin{array}{c}\text { Valor teórico } \\
\text { DOGEN }\end{array}$ & $\begin{array}{c}\text { Valoz teórico } \\
\text { DOGEN } \\
\text { 2a }\end{array}$ \\
\hline \hline Raio interior & $\mathbf{5 9 , 6 1}$ & 59,60 & 55,31 & 58,25 & 59,24 & 65,43 \\
\hline Lado da figura & $\mathbf{8 4 , 2 9}$ & 84,29 & 78,22 & 82,38 & 83,79 & 92,56 \\
\hline Garganta & $\mathbf{1 1 , 7 2}$ & 12,46 & 8,69 & 10,77 & 12,03 & 16,66 \\
\hline Flanco & $\mathbf{1 2 , 5 6}$ & 14,47 & 7,56 & 7,58 & 12,55 & 9,70 \\
\hline Face & $\mathbf{3 4 , 8 1}$ & 30,82 & 22,99 & 25,96 & 34,79 & 34,70 \\
\hline Cabeça & $\mathbf{3 0 , 2 1}$ & 25,66 & 19,11 & 20,22 & 30,52 & 24,34 \\
\hline Cortina & $\mathbf{6 0 , 8 4}$ & 59,38 & 60,84 & 60,84 & 59,74 & 59,23 \\
\hline Segundo flanco & $\mathbf{1 1 , 6 4}$ & 0,00 & 32,59 & 32,54 & 12,90 & 15,29 \\
\hline Lado exterior & $\mathbf{1 2 6 , 9 7}$ & 120,58 & 105,25 & 110,99 & 126,97 & 126,97 \\
\hline
\end{tabular}




\begin{tabular}{l|l|ccc:c:c}
\hline Defesa flancante & $\mathbf{9 6 , 3 1}$ & 90,63 & 52,23 & 55,25 & 95,82 & 94,67 \\
\hline Defesa fichante & $\mathbf{8 5 , 0 3}$ & 0,00 & 84,13 & 87,09 & 83,29 & 79,68 \\
\hline
\end{tabular}

Tabela 9. Comparação entre valor teórico dos modelos de fortificação a partir dos Tratados do século XVII com o valor da média das medidas da fortificação. Forte Santa Cruz de Itamaracá, 1654.

\begin{tabular}{|c|c|c|c|c|c|c|}
\hline $\begin{array}{l}\text { Medidas angulares } \\
\text { (Graus decimais) }\end{array}$ & $\begin{array}{l}\text { Fortificação } \\
\text { Média }\end{array}$ & $\begin{array}{c}\text { Valor teórico } \\
\text { SCAMOZZI } \\
\text { Castelo e Cidadela }\end{array}$ & $\begin{array}{l}\text { Valor teórico } \\
\text { GOLDMAN } \\
\text { F.Quadrantal }\end{array}$ & $\begin{array}{c}\text { Valor teórico } \\
\text { GOLDMAN } \\
\text { Meio Forte }\end{array}$ & $\begin{array}{c}\text { Valor teórico } \\
\text { DOGEN } \\
\text { Fortaleza da } \\
1 \mathrm{a} \mathrm{e} 2 \mathrm{a} \\
\end{array}$ & $\begin{array}{l}\text { Valor teórico } \\
\text { DOGEN } \\
\text { Fortaleza da 3a }\end{array}$ \\
\hline Ângulo do centro & $90,0^{\circ}$ & $90,0^{\circ}$ & $90,0^{\circ}$ & $90,0^{\circ}$ & $90,0^{\circ}$ & $90,0^{\circ}$ \\
\hline Ângulo da figura & $90,0^{\circ}$ & $90,0^{\circ}$ & $90,0^{\circ}$ & $90,0^{\circ}$ & $90,0^{\circ}$ & $90,0^{\circ}$ \\
\hline Ângulo do baluarte & $60,6^{\circ}$ & $76,31^{\circ}$ & $60,0^{\circ}$ & $60,0^{\circ}$ & $60,0^{\circ}$ & $60,0^{\circ}$ \\
\hline Ângulo flancante & $14,6^{\circ}$ & $6,84^{\circ}$ & $15,0^{\circ}$ & $15,0^{\circ}$ & $15,0^{\circ}$ & $15,0^{\circ}$ \\
\hline Ângulo cabeça/garganta & $135,0^{\circ}$ & $135,0^{\circ}$ & $135,0^{\circ}$ & $135,0^{\circ}$ & $135,0^{\circ}$ & $135,0^{\circ}$ \\
\hline Ângulo face/flanco & $101,9^{\circ}$ & $96,84^{\circ}$ & $105,0^{\circ}$ & $105,0^{\circ}$ & $105,0^{\circ}$ & $105,0^{\circ}$ \\
\hline Ângulo flanco/cortina & $87,2^{\circ}$ & $90,0^{\circ}$ & $90,0^{\circ}$ & $90,0^{\circ}$ & $90,0^{\circ}$ & $90,0^{\circ}$ \\
\hline Inclinação & $\mathbf{7 8 , 7 ^ { \circ }}$ & $63,43^{\circ}$ a $71,57^{\circ}$ & $63,43^{\circ}$ & $63,43^{\circ}$ & $63,43^{\circ}$ & $63,43^{\circ}$ \\
\hline
\end{tabular}

Tabela 10. Comparação entre valor teórico dos modelos de fortificação a partir dos Tratados do século XVII com o valor da média das medidas da fortificação. Forte Santa Cruz de Itamaracá, 1654.

Num segundo momento de análise, as plantas baixa das fortificações e a planta do modelo que mais se aproximou foram sobrepostas para tentar confirmar a constatação realizada a partir das medidas. No caso da verificação ser confirmada, atribuiu-se o modelo selecionado como modelo de referência para a construção da fortificação, como foi o caso do Forte de Santa Cruz de Itamaracá e do modelo de Matthias Dogen ${ }^{9}$ (Figura 15).

${ }^{9}$ Matthias Dogen (1605-1672), arquiteto militar, Um dos teóricos que representava a Escola holandesa de fortificação, Dogen projetou na muralha e nos baluartes, em terra, para serem muito 


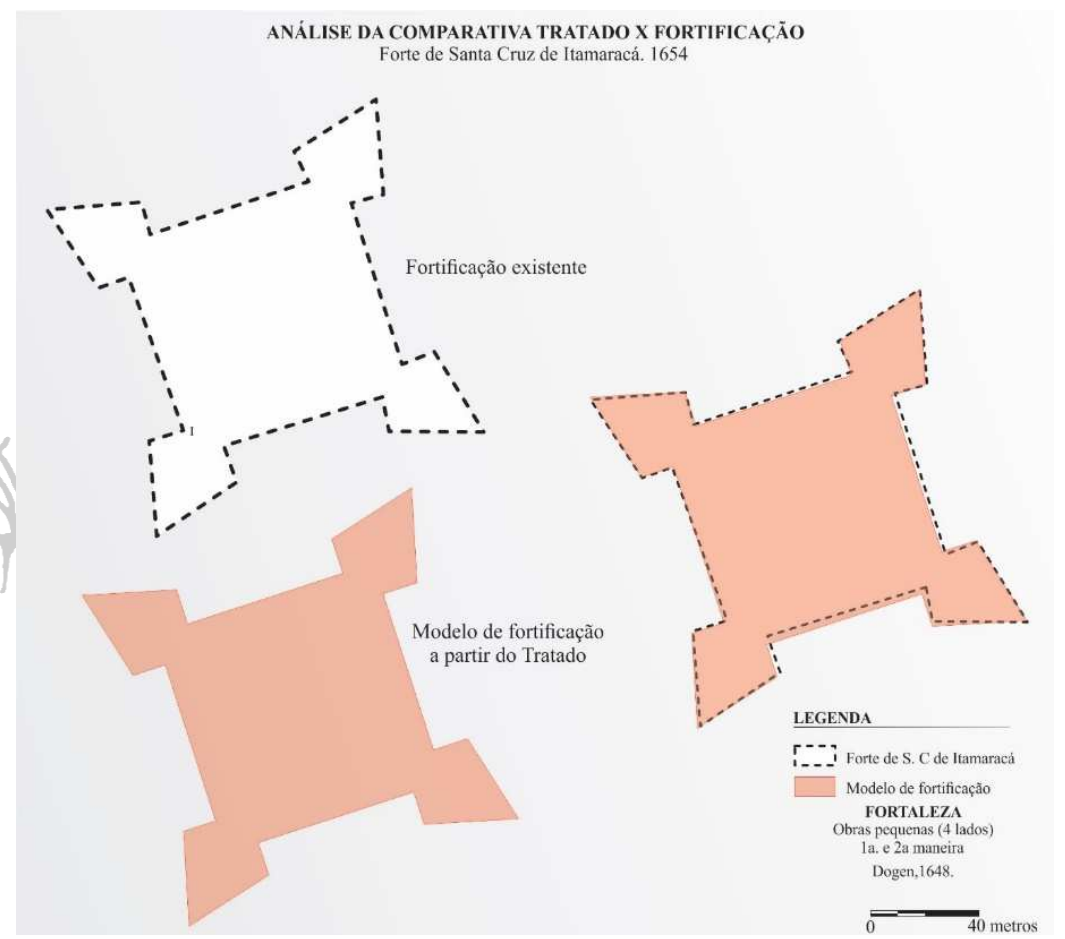

Figura

Sobreposição 15. planta do Forte de Santa Cruz de Itamaracá com a planta do modelo de Matthias Dogen selecionado a partir da comparação dos valores das suas medidas lineares e angulares.

Na comparação das medidas lineares e angulares para o Forte do Brum verificouse que as medidas lineares estão mais próximas aos valores das medidas do modelo denominado Castelo e Cidadela, de formato quadrangular, criado por Vicenzo Scamozzi. No entanto, na comparação dos valores das medidas angulares yerificouse que os valores das medidas da fortificação estão mais próximos aos valores das medidas de todos os outros modelos. Significando que nenhum dos modelos utilizados na análise foi empregado para construção do Forte do Brum. No caso do 
Forte de Santo Inácio de Loyola de Tamandaré e do Forte de São Tiago das Cinco Pontas, verificou-se que as medidas lineares e angulares estão mais próximos àquelas do modelo denominado Fortaleza, de formato quadrangular, cujas dimensões e proporções são da $1^{\mathrm{a}}$. e $2^{\mathrm{a}}$. maneira de calcular as medidas das fortificações, criado por Dogen. O mesmo modelo utilizado no Forte de Santa Cruz de Itamaracá.

\section{Resultado da Classificação quanto à eficácia bélica}

Considerando os resultados das análises acima realizadas, é possível fazer algumas reflexões sobre a eficácia bélica das fortificações construídas na segunda metade do século XVII, após a capitulação holandesa. A verificação de mudanças na capacidade que tem uma fortificação de cumprir sua função precípua: se defender e defender um determinado lugar, indica uma possível transformação tecnológica nos processos construtivos das fortificações de Pernambuco do período em discussão.

Considerando, portanto, o fato de que no Terceiro Sistema Defensivo Português foi utilizado o tipo de Fortificação Moderna, abaluartada, constata-se que a utilização desse tipo de fortificação está adequada ao tipo de armas de fogo que se usava na Europa: a artilharia pirobalística com poder de destruição. As Fortificações Modernas, com suas muralhas formadas por reparos baixos, largos e maciços, foram desenvolvidas para resistir ao impacto das balas dos canhões. A eficácia bélica de uma Fortificação Moderna, portanto, já é maior que a de uma Fortificação 
de Transição, independente do modelo. Contudo, com a utilização do modelo abaluartado, esse incremento na eficácia bélica foi maior, pois está relacionado à formação de linhas flancantes: elemento não explorado no primeiro sistema defensivo antes da invasão holandesa (1630) e pouco explorado no segundo momento defensivo, período de dominação holandesa (1630 a 1654).

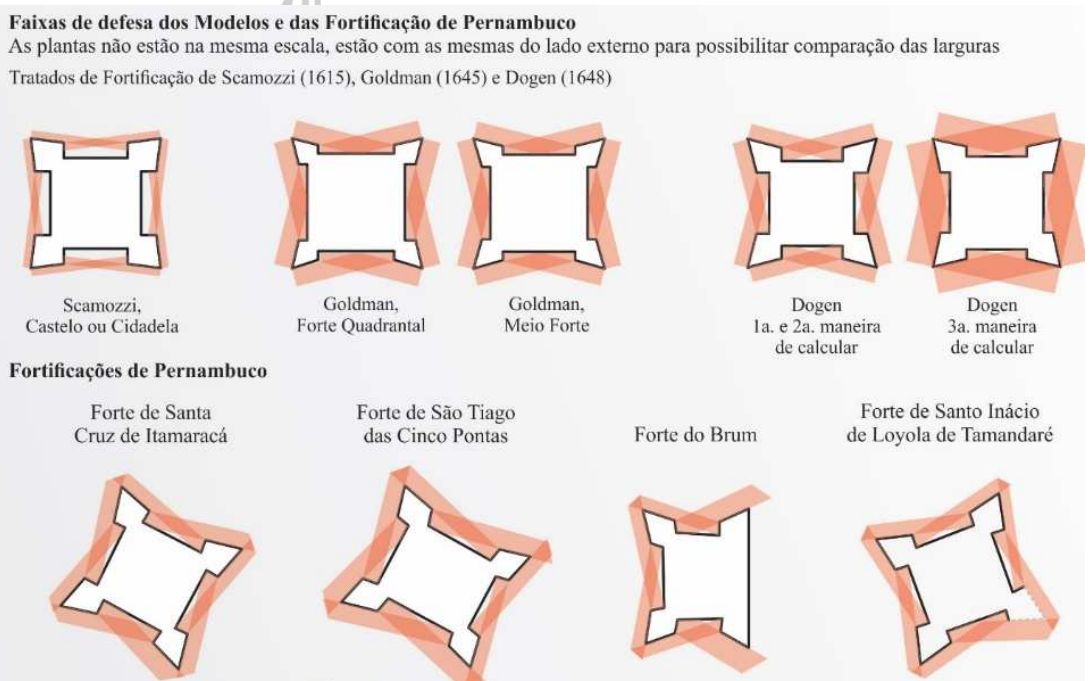

Figura

16.

Representação das faixas de defesa nos modelos europeus e nas fortificações de Pernambuco (plantas com a mesma medida do lado externo para permitir comparar a largura das faixas).

\section{A utilização de Tratados na construção das fortificações em Pernambuco}

Continuando as nossas reflexões, especificamente sobre a utilização de Tratados pelos portugueses ao longo dos séculos XVI e XVII, vale ressaltar que os modelos oriundos de Tratados sobre fortificações foram utilizados neste terceiro Sistema Defensivo. Diferentemente dos modelos utilizados no primeiro e segundo Sistemas Defensivos, esses já eram mais complexos e, portanto, eram objeto de apresentação 
nos $\operatorname{Tratados}^{10}$. A análise realizada pela comparação entre modelos e fortificações revelou que o Forte de Santa Cruz de Itamaracá, o Forte de São Tiago das Cinco Pontas e o Forte de Santo Inácio de Loyola de Tamandaré podem ser produto de um mesmo Tratado holandês, de autoria de Matthias Dogen. Essas três fortificações foram construídas após a capitulação holandesa, sugerindo que possa ter havido alguma influência ${ }^{11}$.

No entanto, deve-se questionar até que ponto chegou a influência da tratadística holandesa na construção de fortificações em Pernambuco. Apesar do levantamento das fortificações ter identificado a utilização do modelo de fortaleza de Matthias Dogen (exceto no Forte do Brum), todas essas fortificações, incluindo o Forte do Brum, estão construídas ou ao menos revestidas em pedra, utilizando rocha calcária ou arenítica. Essa não é uma recomendação da tratadística da escola holandesa. Pelo contrário, os holandeses eram categóricos em defender a terra como o material mais adequado para se construir uma fortificação. O encamisamento do reparo em terra, utilizando a pedra ou tijolo como revestimento, era uma recomendação dos tratadistas italianos. Por fim, deve-se ressaltar que, as obras do reparo dessas fortificações, em todos os sistemas construtivos, executaram os taludes com inclinação que variava de $76,5^{\circ}$ a $78,7^{\circ}$, inclinação que não era a recomendada nos

\footnotetext{
${ }^{10}$ Os modelos simplificados, sem baluartes, não estavam apresentados em todos os Tratados, provavelmente por já serem bem conhecido entre os profissionais envolvidos com a guerra.

${ }^{11}$ Regisra-se que a influência holandesa pode não ter sido resultado apenas da presença holandesa na Capitania, pode também ter sido resultado da cooperação militar acordada entre Portugal e Holanda, no âmbito do primeiro Tratado de Haia, de 1641.
} 
tratados do século XVII: os autores indicavam, unanimemente, a inclinação de $63,43^{\circ}$. Essa inclinação maior era usual entre os tratadistas no século XVI, como Girolamo Maggi e Sebastiano Serlio e Carlo Theti.

Quanto à utilização de Tratados europeus em Pernambuco, portanto, pode-se concluir que essa foi uma prática dos colonizadores. No entanto, não houve obediência a um único Tratado; já se observava na prática portuguesa na Capitania, a tendência da segunda metade do século XVII em toda a Europa, ou seja, a consulta a diversos tratados enquanto referências para produzir um novo modelo, que pode ser chamado de híbrido, mas pode também ser considerado um modelo original português em Pernambuco.

\section{CONCLUSÃO}

Para entender por que se construíram fortificações modernas e abaluartadas apenas a partir da segunda metade do século XVII, embora se conhecessem esses tipos de plantas desde o século XVI, há que se considerar os materiais disponíveis, o modelo de colonização e os recursos disponíveis.

Uma explicação mais simples poderia basear-se na falta de conhecimento técnico e especializado dos portugueses. Entretanto, no caso das fortificações construídas em Pernambuco em períodos anteriores a 1654 essa justificativa é insuficiente, uma vez que houve investimento da metrópole para assimilar novos modelos construtivos de fortificações. Essa circunstância é perceptível desde o início do século XV, quando 
em Portugal já se tem notícias de preceptores italianos para os nobres, além de intelectuais estrangeiros, que eram chamados pelo Governo e pela Igreja, para atuar em território português e nas colônias. Assim, Portugal também estava se preparando para defender seu Império: foram ainda traduzidos tratados, contratados estrangeiros, enviados engenheiros para a Itália. Foi feito todo um esforço para a formação de profissionais na arte da guerra, (Wehling. 1999: p. 21 e 36).

De maneira semelhante o alto custo que poderiam representar uma fortificação dita moderna também é insuficiente como justificativa do atraso de sua adoção na antiga colônia. Mas ao levarmos em consideração o contexto da colonização da época, especialmente do comércio, percebe-se que o Brasil era considerado uma colônia de segunda categoria pois, desde o século XVI e o início do XVII, os interesses estavam no Oriente que provinha mais benefícios através de seus entrepostos e rotas bem consolidadas. Ocorre que Portugal ainda não estava interessado ou talvez convencido da capacidade do Brasil lhe prover benefícios reais, e por isso preocupava-se mais com suas colônias mais rentáveis do Oriente. Ou seja, o alto investimento requerido no Brasil talvez não compensasse. Há ainda que se pensar na questão dos colonos, e que tinham investido recursos e suas vidas no vasto litoral da colônia brasileira. Mas porque, então, praticamente não investiram recursos na defesa dos territórios ocupados antes de 1654? Não financiaram obras de fortificação mais eficazes durante os períodos de iminente invasão e durante a dominação holandesa? Afinal, a produção de açúcar de Pernambuco ainda contava com resultados satisfatórios, apesar de já começar a apresentar uma tênue 
concorrência do açúcar de beterraba, mas por outro lado o tráfico de escravos já começava a ser uma atividade muito rentável. A explicação, portanto, não é fácil.

O fato é que só nesse terceiro momento, após a capitulação holandesa, é que Portugal passou a ter uma preocupação proporcional a exigida pela sua maior colônia e a investir no seu Sistema Defensivo. Pernambuco passou a contar com onze fortificações, destas, sete eram pequenas e frágeis, mas quatro eram mais robustas, pois foram construídas abaluartadas, como recomendavam os tratados. Essas fortificações apresentavam o traço holandês, revestimento à italiana e inclinação do talude do século XVI.

Contudo, aquelas quatro fortificações executadas em Pernambuco haviam sido dispendiosas, pois, entre os aprimoramentos implementados utilizaram-se a pedra como revestimento. Deve-se ressaltar ainda, no caso dos Fortes de São Tiago das Cinco Pontas e do Brum, que parte dos arenitos utilizados na sua construção foram extraídas de fontes que estavam até há mais de $15 \mathrm{~km}$ de distância, demonstrando que houve um grande investimento na construção dessas duas fortificações.

Não se pode deixar de considerar que na segunda fase, (entre 1630 até 1654, durante a ocupação holandesa) percebe-se um maior investimento dos governantes e lideranças locais na defesa de Pernambuco. Mas nada de muito mais significativo do que as fortificações construídas no primeiro sistema defensivo da antiga colônia. Naquele período foram construídas oito fortificações, todas ainda pequenas e 
frágeis, apesar de já terem surgidos formatos que propiciavam a formação de linhas de defesa ou linhas flancantes.

Nesse contexto e ao levarmos em consideração que Sistema Defensivo pode ser tanto um conjunto de fortificações e estruturas de defesa quanto suas tropas e as embarcações que as protegem, o contexto político e econômico atrelado aos dados físicos dos materiais e dos levantamentos geométricos permitiu identificar que as escolhas tecnológicas das fortificações em Pernambuco materializam um aspecto da colonização. Ocorre que Portugal ainda não estava interessado ou talvez convencido da capacidade do Brasil de lhe prover benefícios reais e investir na efetiva proteção do litoral não lhe parecia uma prioridade. Os holandeses trataram de demostrar o contrário.

Assim nos três momentos estudados - antes, durante e após a capitulação dos holandeses - inicialmente, ao longo do século XVI e primeira metade do século XVII, a Metrópole não disponibilizou os elementos necessários à instaláção de um Sistema Defensivo eficaz em Pernambuco. Os investimentos necessários só foram realizados após a capitulação holandesa (1654). Nesse terceiro momento, Portugal teria voltado sua atenção para as colônias do Atlântico e o Brasil passou a contar com fortificações, tropas e navios necessários à defesa da Capitania.

Pode-se concluir, portanto, que a construção de fortificações em Pernambuco significou, ao mesmo tempo, uma obsolescência e uma evolução tecnológica. 
Observando essas fortificações em relação às fortificações que se construíam no mundo, naquele momento, aquelas de Pernambuco utilizaram tipos ultrapassados considerando sua capacidade de se defender da artilharia pirobalística com efeito de destruição. No entanto, observando essas fortificações no âmbito de própria Capitania, verificou-se uma evolução tecnológica na medida em que se observa a tendência de aumento de sua eficácia bélica, desde o século XVI e durante o século XVII.

\section{REFERÊNCIAS BIBLIOGRÁFICAS}

BASSALA, George. La evolucion de la tecnologia. Barcelona: Editorial Crítica, 1991. 249p.

BOXER, C. R. O império colonial português (1415-1825). São Paulo: Edições 70, 1969. 406p.

BRANDÃO, Augusto Pereira. O Oriente. In: História das fortificações portuguesas no mundo. Rafael Moreira (org). Lisboa: Publicações Alfa, 1989. p. 159-187.

CAVAlCANTI, Vanildo Bezerra. Recife do Corpo Santo. 2a $2^{\mathrm{a}}$ ed. Recife: Bagaço, 2009.397p.

COELHO, Duarte de Albuquerque. Memórias diárias da guerra do Brasil: 1630-1638. $2^{\mathrm{a}}$. ed. Recife, Fundação de Cultura da Cidade do Recife, 1982. 366p.

DANTAS, José Robinson Alcoforado; LIMA FILHO, Clóvis. Síntese da Geologia de Pernambuco. Departamento Nacional de Produção Mineral. $4^{\circ}$ Distrito, Pernambuco 2006. Acessado em 18/08/2014 pelo site http://www.dnpm-pe.gov.br/Sint_PE/Indice.php.

DOGEN, Matthias. L'Architectura Militair e Moderne ou Fortification. Amsterdã, 1648. 548p 
GALLAY, Alain. A arqueologia amanhã. Tradução de Emílio Fogaça do original L'archéologie demain. Paris: Pierre Belfont Ed., 1986. 324p.

GAMA, Ruy. A tecnologia e o trabalho na história. São Paulo: Nobel: Editora da Universidade de São Paulo, 1986. 207p.

GOLDMAN, Nicolas. La Nouvelle Fortification. Leiden, 1645. 224p.

Guia de inventário - Fortificações medievais e modernas. Sacavém: IHRU/SIPA, 2015.120p.

MENEZES, José Luiz Mota. RODRIGUES, Maria do Rosário Rosa. Fortificações portuguesas no Nordeste do Brasil. Séculos XVI, XVII e XVIII. Recife: Pool. Editorial S/A, 1986. 158p.

OLIVEIRA, Bernardo J. de. Francis Bacon e a fundamentação da ciência como tecnologia. Belo Horizonte: Editora UFMG, 2002. 277p.

QUINTANILLA, Miguel Ángelo. Tecnología: un enfoque filosófico y outros ensayos de filosofia de la tecnologia. México: FCE, 2005. 296p.

RENFREW, Collin. Towards a cognitive archaeology. In: The ancient mind.: p.3-11.2001.

SCAMOZZI, Vicenzo. L' Idea della Architettura Universale. Veneza, 1615. 391p. Schumann, 1972: p. 34).

TONERA, Roberto. O Sistema Defensivo da Ilha de Santa Catarina - Brasil: Criação, Abandono e Recuperação. Conferência proferida no 1er. Seminario regional de ciudades amuralladas - 6 e 7 de abril de 2005, Montevideo, Uruguay.

http://www.fortalezas.ufsc.br/6seminario/index.php

WEHLING, Arno. WEHLING, Maria José C. M. Formação do Brasil colonial. Rio de Janeiro: Nova Fronteira, 1999. 401p. 